\title{
Thermal and Exergetic Analysis of Metal Foam-enhanced Cascaded Thermal Energy Storage (MF-CTES)
}

\author{
Y. Tian ${ }^{\text {a }}$ C.Y. Zhao ${ }^{\text {b }}$ \\ ${ }^{a}$ School of Engineering, University of Warwick, CV4 7AL Coventry, UK \\ Email: Y.Tian.4@warwick.ac.uk \\ ${ }^{\mathrm{b}}$ School of Mechanical Engineering, Shanghai Jiaotong University, 200240 Shanghai, China \\ Email: Changying.zhao@sjtu.edu.cn
}

Article history:

Received 13 August 2012

Revised 9 November 2012

Accepted 9 November 2012

Available online 7 December 2012

Doi: http://dx.doi.org/10.1016/j.ijheatmasstransfer.2012.11.034

\section{Cited as:}

Y Tian, CY Zhao. Thermal and exergetic analysis of Metal Foam-enhanced Cascaded Thermal Energy Storage (MF-CTES). International Journal of Heat and Mass Transfer 58 (2013): 86-96.

\begin{abstract}
Metal Foam-enhanced Cascaded Thermal Energy Storage (MF-CTES) has been proposed to solve the problem of poor heat transfer during heat exchange process, which is caused by unavoidable decrease of temperature differences. This paper conducts a theoretical study examining the overall thermal performance of STES (Single-stage Thermal Energy Storage), CTES (Cascaded Thermal Energy Storage) and MF-CTES, with both heat exchange rate and exergy efficiency being considered. The main findings are: heat exchange rate of STES is improved by CTES (up to 30\%), and is further improved by MF-CTES (by 2-7 times); exergy efficiency of STES cannot be significantly improved by CTES $(-15 \%$ to $+30 \%)$, nor by MF-CTES; exergy transfer rate of STES is increased by CTES (up to 23\%), and is further increased by MF-CTES (by 2-7 times).
\end{abstract}

Keywords: Metal foam; Heat transfer enhancement; Exergy; Cascaded Thermal Energy Storage; Brinkman-Forchheimer; Enthalpy method. 


\section{Highlights}

- Metal Foam-enhanced Cascaded Thermal Energy Storage (MF-CTES) has been proposed to enhance energy and exergy efficiency.

- Three systems are compared: STES (Single-stage Thermal Energy Storage), CTES (Cascaded Thermal Energy Storage) and MF-CTES.

- Heat transfer rate of STES is improved by CTES (up to 30\%), and is further improved by MF-CTES (by 2-7 times).

- Exergy efficiency of STES cannot be improved significantly by CTES (-15\% to $+30 \%)$, nor by MF-CTES;

- Exergy transfer rate of STES is increased by CTES (up to 23\%), and is further increased by MF-CTES (by 2-7 times). 
Table of Contents

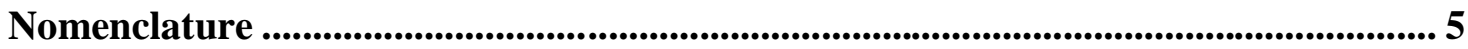

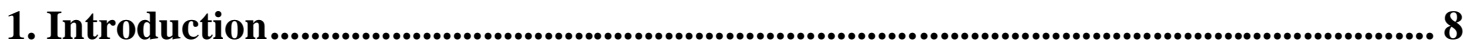

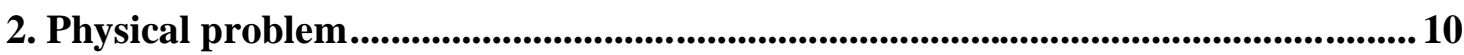

3. Mathematical description................................................................................. 10

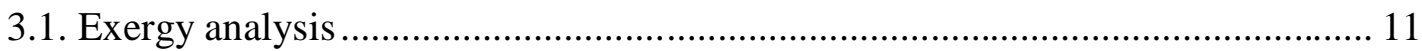

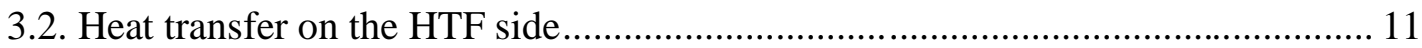

3.3. Heat transfer between HTF and PCM-metal foam. ............................................. 12

3.4. Heat transfer on the PCM-metal foam side......................................................... 14

3.4.1. Equations of fluid dynamics......................................................................... 14

3.4.2 Equations of phase change heat transfer .................................................... 16

3.4.3. The initial and boundary conditions....................................................... 17

3.4.4. Modelling of metal foam microstructures................................................... 18

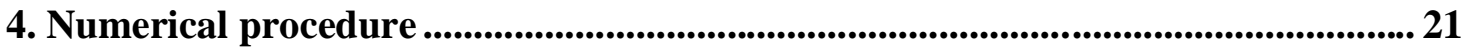

5. Results and discussion .................................................................................................................... 22

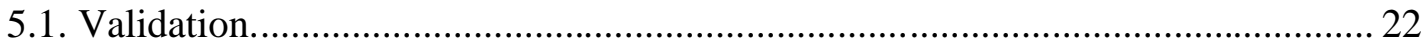

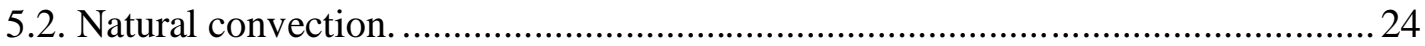

5.3. Comparison of equivalent heat exchange rates among STES, CTES and MF-CTES.

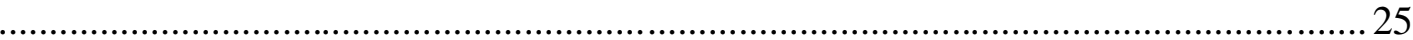

5.4. Comparison of exergy efficiency among STES, CTES and MF-CTES............... 26

5.5. Comparison of exergy transfer rate among STES, CTES and MF-CTES ............. 27

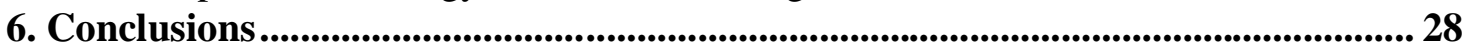

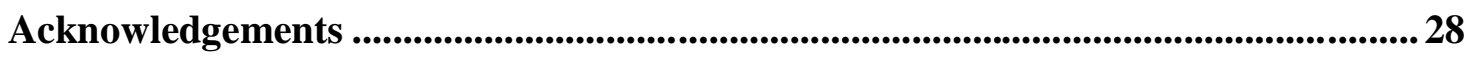

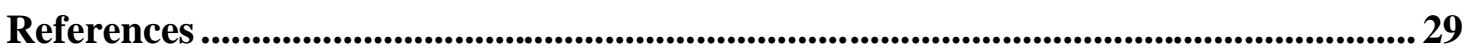

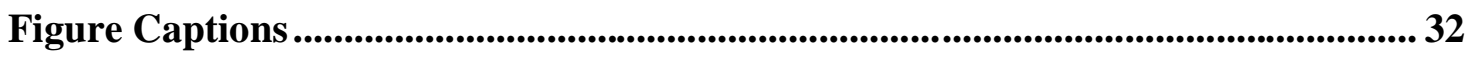

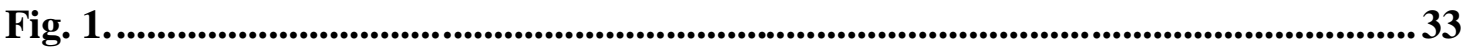

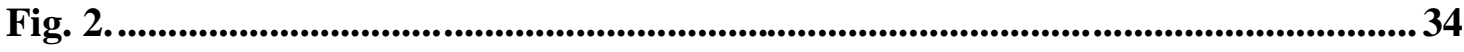

Fig. 3................................................................................................................................................................. 34

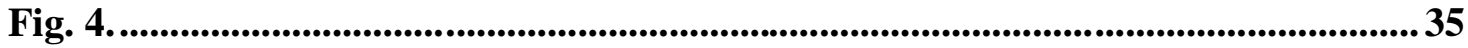

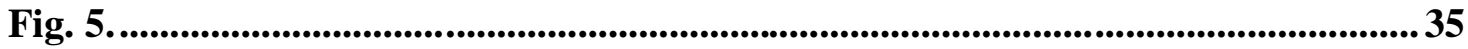

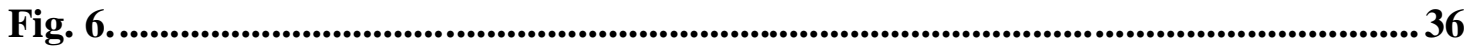

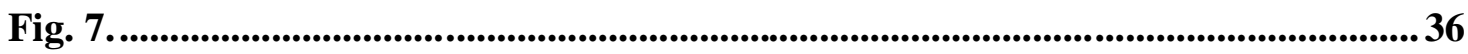

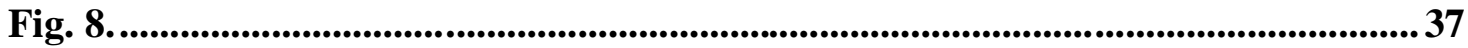

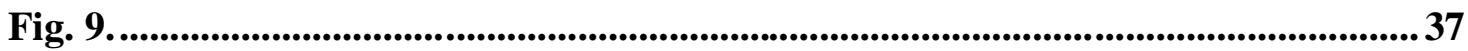

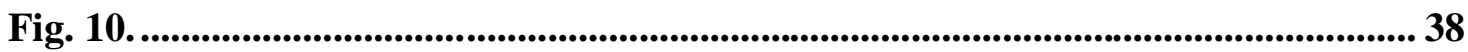




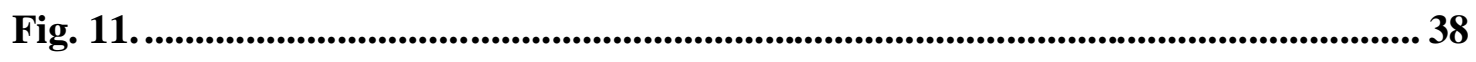

Table Captions .............................................................................................................. 39

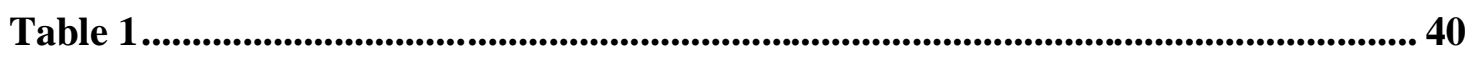

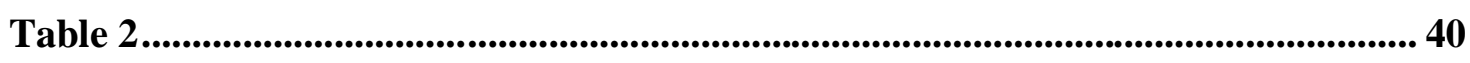

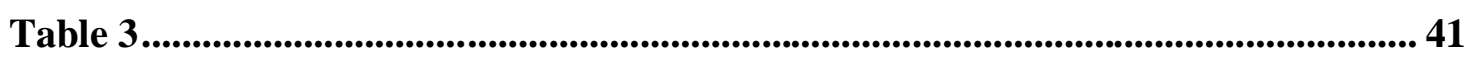




\section{Nomenclature}

\begin{tabular}{|c|c|c|}
\hline$a_{s f}$ & $=$ & specific surface area \\
\hline$B i$ & $=$ & Biot number: $h_{f} d / k_{P C M}$ \\
\hline$c_{f}$ & $=$ & specific heat of Heat Transfer Fluid (HTF) \\
\hline$c_{p}$ & $=$ & specific heat at constant pressure \\
\hline$c_{p . M F}$ & $=$ & specific heat of metal foam \\
\hline$c_{p . P C M}$ & $=$ & specific heat of Phase Change Material (PCM) \\
\hline$C_{f}$ & $=$ & inertia coefficient of fluid flow in metal foams \\
\hline$d$ & $=$ & characteristic length \\
\hline$d_{f}$ & $=$ & equivalent diameter of metal fibre \\
\hline$d_{p}$ & $=$ & equivalent pore size \\
\hline$d A$ & $=$ & heat transfer area element \\
\hline$e$ & $=$ & length ratio of cubic juncture node to ligament \\
\hline g & $=$ & gravity constant \\
\hline$h_{e x}$ & $=$ & effective exergy transfer rate \\
\hline$h_{P C M}$ & $=$ & specific enthalpy of PCM \\
\hline$h_{f}$ & $=$ & effective heat transfer coefficient for HTF \\
\hline$h_{s f}$ & $=$ & interstitial heat transfer coefficient \\
\hline$h_{1,2}$ & $=$ & system dimensions in $y$-axis \\
\hline$H_{L}$ & $=$ & latent heat \\
\hline$k_{f}$ & $=$ & thermal conductivity of fluid saturated in metal foams \\
\hline$k_{f e}$ & $=$ & effective thermal conductivity for PCM \\
\hline$k_{P C M}$ & $=$ & thermal conductivity of PCM \\
\hline$k_{s}$ & $=$ & thermal conductivity of the metal material in metal foam \\
\hline$k_{s e}$ & $=$ & effective thermal conductivity for metal foam \\
\hline$K$ & $=$ & permeability \\
\hline$L_{1,2,3}$ & $=$ & system dimension in $x$-axis \\
\hline$N u$ & $=$ & Nusselt number: $h_{f} d / \lambda_{H T F}$ \\
\hline & $=$ & pressure \\
\hline
\end{tabular}

$\mathrm{m}^{-1}$

(dimensionless)

$\mathrm{kJ} /\left(\mathrm{kg}^{\circ} \mathrm{C}\right)$

$\mathrm{kJ} /\left(\mathrm{kg}^{\circ} \mathrm{C}\right)$

$\mathrm{kJ} /\left(\mathrm{kg}^{\circ} \mathrm{C}\right)$

$\mathrm{kJ} /\left(\mathrm{kg}^{\circ} \mathrm{C}\right)$

(dimensionless)

$\mathrm{m}^{2}$

(dimensionless)

$\mathrm{m} / \mathrm{s}^{2}$

$\mathrm{W} / \mathrm{m}^{2}$

$\mathrm{kJ} / \mathrm{kg}$

$\mathrm{W} / \mathrm{m}^{2}$

$\mathrm{W} /\left(\mathrm{m}^{2} \mathrm{~K}\right)$

$\mathrm{m}$

$\mathrm{kJ} / \mathrm{kg}$

$\mathrm{W} /(\mathrm{m} \mathrm{K})$

$\mathrm{W} /(\mathrm{m} \mathrm{K})$

$\mathrm{W} /(\mathrm{m} \mathrm{K})$

$\mathrm{W} /(\mathrm{m} \mathrm{K})$

$\mathrm{W} /(\mathrm{m} \mathrm{K})$

$\mathrm{m}^{2}$

m

(dimensionless)

$\mathrm{Pa}$ 


\begin{tabular}{|c|c|c|c|}
\hline $\operatorname{Pr}$ & $=$ & Prandtl number: $c_{p} \mu_{H T F} / k_{H T F}$ & (dimensionless) \\
\hline$q$ & $=$ & heat flux, or effective heat transfer rate. & $\mathrm{W} / \mathrm{m}^{2}$ \\
\hline$R_{A, B, C, D}$ & $=$ & thermal resistance & $\left(\mathrm{m}^{2} \mathrm{~K}\right) / \mathrm{W}$ \\
\hline $\operatorname{Re}$ & $=$ & Reynolds number: $\rho u d / \mu$ & (dimensionless) \\
\hline$R_{g}$ & $=$ & ideal gas constant & $\mathrm{kJ} /(\mathrm{kg} \mathrm{K})$ \\
\hline s & $=$ & specific entropy & $\mathrm{kJ} /(\mathrm{kg} \mathrm{K})$ \\
\hline$t$ & $=$ & time & $\mathrm{s}$ \\
\hline$T_{a}$ & $=$ & ambient temperature & ${ }^{\mathrm{o}} \mathrm{C}$ \\
\hline$T_{f}$ & $=$ & temperature function of HTF & ${ }^{\mathrm{o}} \mathrm{C}$ \\
\hline$T_{w}$ & $=$ & wall temperature & ${ }^{\circ} \mathrm{C}$ \\
\hline$T_{P C M}$ & $=$ & temperature function of $\mathrm{PCM}$ & ${ }^{\circ} \mathrm{C}$ \\
\hline$T_{M F}$ & $=$ & temperature function of metal foam & ${ }^{\circ} \mathrm{C}$ \\
\hline$T_{f 0}$ & $=$ & HTF inlet temperature & ${ }^{\circ} \mathrm{C}$ \\
\hline$T_{m}$ & $=$ & melting temperature & ${ }^{\circ} \mathrm{C}$ \\
\hline$u$ & $=$ & the component of flow velocities in $x$-direction & $\mathrm{m} / \mathrm{s}$ \\
\hline$v$ & $=$ & the component of flow velocities in $y$-direction & $\mathrm{m} / \mathrm{s}$ \\
\hline $\mathbf{V}$ & $=$ & velocity vector & $\mathrm{m} / \mathrm{s}$ \\
\hline $\mathrm{X}$ & $=$ & specific anergy & $\mathrm{kJ} / \mathrm{kg}$ \\
\hline \multicolumn{4}{|c|}{ Greek symbols } \\
\hline$\beta$ & $=$ & linear thermal expansion coefficient & $\mathrm{K}^{-1}$ \\
\hline$\varepsilon$ & $=$ & porosity & (percentage) \\
\hline$\eta_{e x}$ & $=$ & exergy efficiency & (percentage) \\
\hline$\lambda$ & $=$ & ratio of ligament radius to ligament length & (dimensionless) \\
\hline$\lambda_{\text {HTF }}$ & $=$ & thermal conductivity of HTF & $\mathrm{W} /(\mathrm{m} \mathrm{K})$ \\
\hline$\rho$ & $=$ & density & $\mathrm{kg} / \mathrm{m}^{3}$ \\
\hline$\mu_{f}$ & $=$ & dynamic viscosity & Pa s \\
\hline$\nabla$ & $=$ & Laplace operator & \\
\hline
\end{tabular}




\section{Subscripts}

$$
\begin{array}{ll}
e & =\text { effective value } \\
f & =\text { HTF } \\
f e & =\text { effective value for PCM } \\
M F & =\text { metal foam } \\
M F-P C M & =\text { metal foam and PCM } \\
r e f & =\text { reference value } \\
\text { se } & =\text { effective value for metal foam }
\end{array}
$$




\section{Introduction}

Efficient utilisation of solar energy is increasingly being considered as a promising solution to global warming and a means of achieving a sustainable development for human beings. Because solar energy has low-density and intermittency, Thermal Energy Storage (TES) plays a pivotal role in balancing energy demand and energy supply. TES technologies rely on high-quality Phase Change Materials (PCMs), which should have high heat storage capacity and excellent heat transfer performance. PCMs have received extensive research interest during the last decade, and they were investigated in a variety of applications: energy saving buildings [1], solar still [2], solar cooker [3, 4], industrial waste heat recovery [5] and solar power plants [6].

Most PCMs have large heat storage capacity, ranging from $90 \mathrm{~kJ} / \mathrm{kg}$ to $330 \mathrm{~kJ} / \mathrm{kg}$ [7], but they suffer from the common problem of low thermal conductivities, being around $0.2 \mathrm{~W} /(\mathrm{m} \mathrm{K})$ for most paraffin waxes and $0.5 \mathrm{~W} /(\mathrm{m} \mathrm{K})$ for most inorganic salts [7]. Low heat transfer performance has been the main factor restricting the application of PCMs in situations which require rapid energy release/storage [8, 9]. Researchers have proposed various methods enhancing heat transfer in PCMs, and these include: incorporating high thermal conductivity enhancers into PCMs [10, 11]; adopting porous heat transfer media [12-16]; Cascaded Thermal Energy Storage (CTES) [17, 18].

High thermal conductivity enhancers including metal fins, metal beads and metal powders improve heat transfer in PCMs, but their enhancement effects are limited to between $60 \%$ and $150 \%$ [11] which is not high enough for most application requirements. Porous media were also used to enhance heat transfer for PCMs, and these include carbon materials and metal foams. Nakaso et al. [15] tested the use of carbon fibres to enhance heat transfer in thermal storage tanks, reporting a twofold rise in effective thermal conductivities. Sari and Karaipekli [13] fabricated a series of the Paraffin/EG (Expanded Graphite) composites, and found that the effective thermal conductivity was increased by 81.2\%-272.7\% depending on the mass fraction of EG added. However, the main disadvantage of EG is its structural discontinuity, which means that heat cannot be transferred very smoothly and efficiently. 
To overcome the structural discontinuity of the Paraffin/EG composites, metal foams have been investigated, as they have continuous metal matrices with porosity ranging from $85 \%$ to $97 \%$, as well as high thermal conductivities. Zhou and Zhao [16] investigated the Paraffin/EG and Paraffin/Metal foam composites to compare their different enhancement effect on PCMs, and concluded that both composites increased heat transfer rate significantly with metal foams showing better performance. The reason accounting for this was later given in a theoretical analysis by Tian and Zhao [19]: the structures inside the expanded graphite are rather sparse (discontinuous), whilst the metal foam matrices are much more continuous so that they can draw heat much more rapidly than expanded graphite.

Cascaded Thermal Energy Storage (CTES), consisting of multiple PCMs with cascaded melting temperatures, has been proposed as a solution to heat transfer deterioration, which often arises when charging/discharging a single-stage PCM storage system. For a single-stage PCM storage system, the temperature of the heat transfer fluid falls rapidly when transferring heat to the PCM; as a result, the temperature difference between heat transfer fluid and the PCM is significantly reduced, which leads to poor heat transfer at the end of the storage [20]. The problem is that the PCM is melted rapidly at the entrance part, but much more slowly at the end of the storage. A similar problem occurs for the discharging process: the PCM at the end of the storage might not be used as the temperature of heat transfer fluid rises. Such problems can be solved by adopting CTES, in which the PCMs with cascaded melting temperatures can help to maintain a relatively high temperature difference.

Gong and Mujumdar [21] investigated a five-stage PCMs system, and found a significantly improved heat transfer $(34.7 \%)$ compared to the single PCM. Michels and Pitz-Paal [6] investigated a three-stage PCM system, and found that a higher proportion of PCMs melted and a more uniform heat transfer fluid outlet temperature than in the traditional single-stage storage. The study by Michels and Pitz-Paal [6] was based on energy efficiency, not having considered exergy efficiency that represents the utilisable part of energy. Exergy analyses for multiple PCM systems were conducted by Watanabe and Kanzawa [17], and Shabgard et al. [22]. Watanabe and Kanzawa [17] found increased exergy efficiency by using multiple PCMs, whilst Shabgard et al. [22] found 
that the multiple PCMs recovered more amount of exergy despite of having lower exergy efficiency at times. A thermal analysis taking exergy into account does not only consider the quantity of energy, but also the quality of energy, and therefore is very important. However, there are only a few publications addressing exergy issues for CTES; none of these studies has combined CTES with other heat transfer enhancement techniques, especially the use of metal foams. This paper aims to investigate, for the first time, the idea of the metal foam-enhanced CTES system, examining its technical feasibility and evaluating its energy and exergy performance.

\section{Physical problem}

Three systems are presented and compared in this study. They are Single-stage Thermal Energy Storage (STES), Cascaded Thermal Energy Storage (CTES) and Metal Foam-enhanced Cascaded Thermal Energy Storage (MF-CTES), which are illustrated in Figs. 1(a), (b) and (c), respectively. STES is formed by a single PCM, which is PCM 4 shown in Fig. 1(a). Both CTES and MF-CTES are formed by staging three PCMs along the HTF (heat transfer fluid) flow direction: PCM 1, 2 and 3 shown in Figs. 1(b) and (c). CTES and MF-CTES are made of the same PCMs, with the only difference being that MF-CTES uses metal foam to enhance heat transfer. The thermo-physical properties of these PCMs used are listed in Table 1 [23].

In Fig. 1, $\mathrm{H}_{\mathrm{L}}(\mathrm{kJ} / \mathrm{kg})$ and $\mathrm{T}_{\mathrm{m}}\left({ }^{\circ} \mathrm{C}\right)$ denote the latent heat and melting temperature, respectively; $h$ and $L$ denote system dimensions. The HTF enters each system from the left (inlet temperature $T_{f 0}=100^{\circ} \mathrm{C}$ ), and exits from the right with the outlet temperature $T_{f}(t)$ which varies with time. The melting temperature of PCM 4 (in STES) was chosen to have the average value of the melting temperatures of PCM 1, 2 and 3, so that a comparison between the three systems is justified. The initial temperatures of all three systems are equal to the ambient temperature, which is $20^{\circ} \mathrm{C}$. Other parameters for the systems are given in Table 2.

\section{Mathematical description}




\subsection{Exergy analysis}

The entropy change [24] of a thermal system from state ' 1 ' to state '2' can be written as:

$$
s_{2}-s_{1}=c_{p} \ln \left(T_{2} / T_{1}\right)-R_{g} \ln \left(p_{2} / p_{1}\right)+H_{L} / T_{m}
$$

The last term on the right hand side of Eq. (1) stands for the entropy change if a phase change process is involved. $H_{L}(\mathrm{~kJ} / \mathrm{kg})$ is the phase change enthalpy and $T_{m}\left({ }^{\circ} \mathrm{C}\right)$ is the phase change temperature.

The unusable part of energy (i.e. anergy X), depending on the entropy increase (irreversibility), can then be written as [24]:

$$
\left.X=T_{a}\left(s_{2}-s_{1}\right)=T_{a_{-}}{ }_{-}^{-} c_{p} \ln \left(T_{2} / T_{1}\right)-R_{g} \ln \left(p_{2} / p_{1}\right)+H_{L} / T_{m}\right]
$$

Thus the proportion of the usable energy can be calculated by Eq. (3):

$$
\eta_{e x}=\frac{c_{p}\left(T_{2}-T_{1}\right)-X}{c_{p}\left(T_{2}-T_{1}\right)}
$$

Substituting Eq.(2) into Eq. (3), exergy efficiency is given in Eq. (4):

$$
\eta_{e x}=\frac{\left.c_{p}\left(T_{2}-T_{1}\right)-T_{a_{-}}{ }_{-} c_{p} \ln \left(T_{2} / T_{1}\right)-R_{g} \ln \left(p_{2} / p_{1}\right)+H_{L} / T_{m}\right]}{c_{p}\left(T_{2}-T_{1}\right)}
$$

Because most PCMs are incompressible,

$$
\eta_{e x}=\frac{c_{p}\left(T_{2}-T_{1}\right)-c_{p} T_{a} \ln \left(T_{2} / T_{1}\right)-T_{a} H_{L} / T_{m}}{c_{p}\left(T_{2}-T_{1}\right)}
$$

This study uses Eq. (5) to obtain the exergy efficiency for all three systems: STES, CTES and MF-CTES.

\subsection{Heat transfer on the HTF side}

Considering a charging process, heat flows from the high-temperature heat transfer fluid (HTF) to low-temperature PCMs. The thermal resistance of heat transfer is made up by two parts: the HTF-side resistance and PCM-side resistance. The approximate value of the Nusselt number $\mathrm{Nu}$ on the HTF side can be obtained by employing the Dittus-Boelter Equation [25].

$$
N u=0.023 \operatorname{Re}^{0.8} \operatorname{Pr}^{0.4}
$$


In this study, water was used as HTF. Table 2 gives the operating parameters of all three energy storage systems. With a flow velocity of $0.5 \mathrm{~m} / \mathrm{s}$, a kinetic viscosity of $0.553 \times 10^{-6} \mathrm{~m}^{2} / \mathrm{s}$, a Prandtl number of 3.56 and a characteristic length of $0.01 \mathrm{~m}$, the heat transfer coefficient $h_{f}$ is given by

$$
h_{f}=\lambda_{\text {нтF }} N u / d
$$

from which $h_{f}=1117.7 \mathrm{~W} / \mathrm{m}^{2}$.

To compare the thermal resistance between the HTF side and PCM side, the Biot number [25] is given by

$$
B i=\frac{h_{f} d}{k_{P C M}}=55.9
$$

This number qualitatively represents how many times larger the thermal resistance is on the PCMs side than on the HTF side. With Bi much greater than 1, the thermal resistance on the HTF side can be reasonably neglected, and this simplifies the following analyses. It should be noted that the obtained $B i$ number is an approximate value, because this study used rectangular ducts, rather than round ducts which were assumed in the DittusBoelter Equation. Even allowing for this, the Bi number will still be much greater than 1, so that the thermal resistance on the HTF side is so low that it can be neglected.

\subsection{Heat transfer between HTF and PCM-metal foam.}

Perfect thermal insulation was assumed in this study, so the heat transfer equations can be established based on energy balance: PCMs absorb the same amount of thermal energy as the HTF releases, which is reflected in Eq. (9).

$$
\begin{aligned}
& \rho_{f} c_{f}\left(h_{2}-h_{1}\right) d A \frac{\partial T_{f}}{\partial x} \frac{\partial x}{\partial t}=\rho_{P C M-M F} h_{1} d A \frac{\partial h_{P C M-M F}}{\partial t} \\
& =h_{1} d A\left[\varepsilon \rho_{P C M} \frac{\partial h_{P C M}}{\partial t}+\rho_{M F} c_{p . M F}(1-\varepsilon) \frac{\partial T_{M F}}{\partial t}\right]
\end{aligned}
$$

Due to $\frac{\partial x}{\partial t}=u_{f}$, Eq. (9) can be re-written as:

$$
\left.\rho_{f} c_{f}\left(h_{2}-h_{1}\right) u_{f} \frac{\partial T_{f}}{\partial x}=h_{1} \varepsilon \rho_{P C M} \frac{\partial h_{P C M}}{\partial t}+\rho_{M F} c_{p . M F}(1-\varepsilon) \frac{\partial T_{M F}}{\partial t}\right]
$$


In order to cope with the phase change heat transfer problem, the enthalpy method has been employed in this study. The correlation between the PCM enthalpy function $h_{P C M}(x$, $y, t)$ and its temperature function $T_{P C M}(x, y, t)$ is given by:

$$
T_{P C M}=\left\{\begin{array}{lc}
\frac{h_{P C M}}{c_{P C M},} & h_{P C M} \in\left(-\infty, c_{P C M} T_{m}\right) \\
T_{m}, & h_{P C M} \in\left(c_{P C M} T_{m}, c_{P C M} T_{m}+H_{L}\right) \\
\frac{h_{P C M}-H_{L}}{c_{P C M}}, & h_{P C M} \in\left(c_{P C M} T_{m}+H_{L},+\infty\right)
\end{array}\right\}
$$




\subsection{Heat transfer on the PCM-metal foam side}

In this section, the governing equations for heat transfer on the PCM-metal foam side, including fluid dynamics equations, phase change heat transfer equations and their initial and boundary conditions will be formulated. The process of solving complicated equations by numerical methods can be significantly simplified if the physical problem is symmetrical. A symmetrical physical problem requires that the computational domain, the initial and boundary conditions, and the governing equations should all be symmetrical. The computational domain for the present study is: $0<x<L_{1}+L_{2}+L_{3}$ and $-h_{1} / 2<y<+h_{1} / 2$ (shown in Fig. 1). Such a rectangular domain is symmetrical with respect to the $x$-axis. The initial and boundary conditions are discussed later in Subsection 3.4.3, which indicates that the upper part (above $x$-axis) has identical initial and boundary conditions to the lower part (below $x$-axis), meaning that the initial and boundary conditions are also symmetrical upon the $x$-axis. However, the present study takes natural convection into account, in which the gravity and temperature differencedriven buoyancy are not symmetrical, so the fluid dynamics equation in $y$-direction is not symmetrical with respect to the $x$-axis. Hence the current physical problem will have to be solved on the whole computational domain.

\subsubsection{Equations of fluid dynamics}

When natural convection takes place, the metal foam still remains stationary, whilst the PCM keeps moving under a buoyancy force driven by temperature difference. To tackle with such complicated PCM flow in the porous metal foam, a volume-averaging technique has been employed [19, 26, 27], for which the classical Continuity Equation is:

$$
\nabla \bullet\langle\mathbf{V}\rangle=\mathbf{0}
$$

Here, \langle\rangle denotes the volume-averaged value of a certain function over an REV (Representative Elementary Volume inside metal foams) [19]. The Continuity Equation takes on the following form under the Cartesian coordinate system:

$$
\frac{\partial u_{P C M}}{\partial x}+\frac{\partial v_{P C M}}{\partial y}=0
$$


Here, $u_{P C M}$ and $v_{P C M}$ denote the components of the velocity $\mathbf{V}$ in $x$-direction and in $y$ direction respectively.

Based on the Brinkman-Forchheimer extended Darcy model [26, 27], the Momentum Equations are given by:

$$
\begin{gathered}
\rho_{P C M} \frac{\partial u_{P C M}}{\partial t}+\frac{\rho_{P C M}}{\varepsilon}\left(u_{P C M} \frac{\partial u_{P C M}}{\partial x}+v_{P C M} \frac{\partial u_{P C M}}{\partial y}\right)=-\frac{\partial p}{\partial x}+ \\
\frac{\mu_{P C M}}{\varepsilon}\left(\frac{\partial^{2} u_{P C M}}{\partial x^{2}}+\frac{\partial^{2} u_{P C M}}{\partial y^{2}}\right)-\frac{\mu_{P C M}}{K} u_{P C M}-\frac{\rho_{P C M} C_{f}}{\sqrt{K}}\left|u_{P C M}\right| u_{P C M} \\
\rho_{P C M} \frac{\partial v_{P C M}}{\partial t}+\frac{\rho_{P C M}}{\varepsilon}\left(u_{P C M} \frac{\partial v_{P C M}}{\partial x}+v_{P C M} \frac{\partial v_{P C M}}{\partial y}\right)=\frac{\partial p}{\partial y}+ \\
\frac{\mu_{P C M}}{\varepsilon}\left(\frac{\partial^{2} v_{P C M}}{\partial x^{2}}+\frac{\partial^{2} v_{P C M}}{\partial y^{2}}\right)-\frac{\mu_{P C M}}{K} v_{P C M}-\frac{\rho_{P C M} C_{f}}{\sqrt{K}}\left|v_{P C M}\right| v_{P C M}+\rho_{P C M} g \varepsilon \beta\left(T_{P C M}-T_{r e f}\right)
\end{gathered}
$$

Here, $\mathrm{g}$ denotes the gravity constant, $\varepsilon$ denotes the porosity of the metal foam, $\mu_{P C M}$ denotes the dynamic viscosity of the PCM, $\rho_{P C M}$ denotes the density of the PCM, $K$ is the permeability coefficient $[26,27], C_{f}$ denotes the inertial factor for fluid flow in metal foams [19, 26, 27], and $\beta$ denotes the thermal expansion coefficient of the PCM.

The PCM flow resistances consist of three parts: firstly, the first-order resistance (Darcy term) which is denoted by the third terms on the right hand side of Eq. (14) and Eq. (15); secondly, the second-order resistance (Forchheimer correction term) which is denoted by the fourth terms on the right hand side of Eq. (14) and Eq. (15); thirdly, the Brinkman viscous resistance which is denoted by the second terms on the right hand side of Eq. (14) and Eq. (15). The last term on the right hand side of Eq. (15) represents the buoyancy force caused by temperature differences inside the PCM, and it is the driving force of natural convection. The intensity of natural convection mainly depends on two factors: driving force and resisting force. The driving force increases with increasing temperature differences, whilst the resisting force can be reduced by decreasing the viscosity $\left(\mu_{P C M}\right)$ of the PCM used. With fixed temperature differences, larger viscosity results in a weaker natural convection. With fixed viscosity, larger temperature differences result in a stronger natural convection. Eqs. (13) - (15) are used to describe the buoyancy-driven fluid flow, but they also hold true when natural convection does not 
take place, which is just a special case when $\mu_{P C M}$ is infinite. The present study treats the non-convection heat transfer region as a special case of natural convection $\left(\mu_{P C M}=+\infty\right)$, so that all cases can use the same equations thus simplifying the subsequent simulation work. When implementing numerical simulation, the program can automatically make the following judgement: if the PCM is still in solid state, its viscosity will be assigned an infinite value to ensure the absence of natural convection; once the PCM finishes melting and becomes liquid, the real value of its viscosity will be assigned, so that the buoyancy forces can be precisely decided.

\subsubsection{Equations of phase change heat transfer}

In order to cope with the phase change heat transfer problem, the Enthalpy Method [19] has been employed in this study. The correlation between the PCM enthalpy function $h_{P C M}(x, y, t)$ and its temperature function $T_{P C M}(x, y, t)$ is given by Eq. (11). Under the Cartesian coordinate system, the Energy Equations for the PCM and metal foam can be written as:

$$
\begin{gathered}
\rho_{M F} c_{p . M F}(1-\varepsilon) \frac{\partial T_{M F}}{\partial t}=k_{s e}\left(\frac{\partial^{2} T_{M F}}{\partial x^{2}}+\frac{\partial^{2} T_{M F}}{\partial y^{2}}\right)-h_{s f} a_{s f}\left(T_{M F}-T_{P C M}\right) \\
\varepsilon \frac{\partial h_{P C M}}{\partial t}+\rho_{P C M} c_{p . P C M} \varepsilon\left(u_{P C M} \frac{\partial T_{P C M}}{\partial x}+v_{P C M} \frac{\partial T_{P C M}}{\partial y}\right)=k_{f e}\left(\frac{\partial^{2} T_{P C M}}{\partial x^{2}}+\frac{\partial^{2} T_{P C M}}{\partial y^{2}}\right) \\
+h_{s f} a_{s f}\left(T_{M F}-T_{P C M}\right)
\end{gathered}
$$

Here, $k_{\text {se }}$ denotes the effective thermal conductivity of metal foam (without PCM embedded), $k_{f e}$ denotes the effective thermal conductivity of the porous PCM (when taking off the metal foam matrix). Their method of calculation is given in subsection 3.4.4. $h_{s f}$ denotes inter-phase heat transfer coefficient between metal ligaments and PCM, and $a_{s f}$ is specific surface area of the metal foam. Their values are obtained by employing the model by Calmidi and Mahajan [27], the detail of which is given in subsection 3.4.4. In Eq. (16) and Eq. (17), the first and second terms on the right hand side represent heat conduction and inter-phase heat transfer, respectively. The second 
term on the left hand side of Eq. (17) represents the convection term for PCM, which equals zero before natural convection occurs $\left(u_{P C M}=v_{P C M}=0\right)$.

\subsubsection{The initial and boundary conditions}

The governing equations in this study are Eqs. (10), (11) and (13)-(17). Their initial conditions are given by:

$$
\begin{gathered}
\left.u_{P C M}\right|_{t=0}=\left.v_{P C M}\right|_{t=0}=0 \\
\left.T_{P C M}\right|_{t=0}=\left.T_{M F}\right|_{t=0}=20^{\circ} \mathrm{C} \\
\left.T_{f}\right|_{t=0}=100^{\circ} \mathrm{C}
\end{gathered}
$$

The boundary conditions are:

$$
\begin{gathered}
u_{P C M},\left.v_{P C M}\right|_{x=0}=u_{P C M},\left.v_{P C M}\right|_{x=L_{1}}=u_{P C M},\left.v_{P C M}\right|_{x=L_{1}+L_{2}}=u_{P C M},\left.v_{P C M}\right|_{x=L_{1}+L_{2}+L_{3}}=0 \\
\left.u_{P C M}\right|_{y= \pm h_{1} / 2}=\left.v_{P C M}\right|_{y= \pm h_{1} / 2} 0 \\
\left.T_{f}\right|_{x=0}=100^{\circ} \mathrm{C}
\end{gathered}
$$

Equations (21) and Eq. (22) give the non-slip boundary conditions of PCM velocities. Eq. (23) gives the HTF temperature $T_{f}$ at its left boundary. $T_{f}$ is a function of only horizontal coordinate $x$ and time $t$, because the thermal resistance of HTF at the $y$ direction can be neglected when $B i$ is much greater than 1, as discussed in Section 3.2.

The heat released from HTF is transferred to PCM and metal foam, but the percentage between PCM and metal foam needs to be carefully decided for an accurate calculation result. Calmidi and Mahajan [27] used an explicit presumption to decide the percentage of the heat absorbed by PCM and metal foam at their common boundary, with PCM being $k_{f e} /\left(k_{s e}+k_{f e}\right) \times 100 \%$ and metal foam being $k_{s e} /\left(k_{s e}+k_{f e}\right) \times 100 \%$. Such presumption can make the simulation simpler and quicker, but meanwhile it results in inaccuracy. Exact percentages between PCM and metal foam should be decided by an implicit relationship, which was given by Tian and Zhao [19] and Zhao et al. [28], shown in Eqs. (24) - (27):

$$
\rho_{f} c_{f}\left(h_{2}-h_{1}\right) u_{f} \frac{\partial T_{f}}{\partial x}=\left.k_{s e} \frac{\partial T_{M F}}{\partial y}\right|_{y=+h_{1} / 2}+\left.k_{f e} \frac{\partial T_{P C M}}{\partial y}\right|_{y=+h_{1} / 2}
$$




$$
\left.T_{M F}\right|_{y=+h_{1} / 2}=\left.T_{P C M}\right|_{y=+h_{1} / 2}=T_{w}
$$

At the upper boundary, Eq. (24) reflects energy conservation between HTF and PCM-metal foam. Here, another restrictive condition is from the temperature continuity both metal foam and PCM should have the same temperature as the wall temperature at their common boundary, as shown in Eq. (25). Such a combined implicit boundary condition shown in Eq. (24) and Eq. (25) can achieve better accuracy due to its avoidance of extra presumption. It needs to be noted that $T_{w}$ in Eq. (25) does not need to be pre-determined, the presence of which is only to show that $T_{M F}=T_{P C M}$. In Eqs. (24) and (25), the number of variables ( $T_{M F}$ and $T_{P C M}$ ) is equal to the number of equations, so the equations are solvable and the solution is finite. Similarly, the boundary conditions for the lower boundary have been obtained as follows:

$$
\begin{gathered}
\rho_{f} c_{f}\left(h_{2}-h_{1}\right) u_{f} \frac{\partial T_{f}}{\partial x}=-\left.k_{s e} \frac{\partial T_{M F}}{\partial y}\right|_{y=-h_{1} / 2}-\left.k_{f e} \frac{\partial T_{P C M}}{\partial y}\right|_{y=-h_{1} / 2} \\
\left.T_{M F}\right|_{y=-h_{1} / 2}=\left.T_{P C M}\right|_{y=-h_{1} / 2}=T_{w}
\end{gathered}
$$

The energy conservation at the lower boundary is shown in Eq. (26), with the temperature continuity condition being given in Eq. (27).

Due to perfect thermal insulation, all four horizontal boundaries are adiabatic, giving:

$$
\begin{gathered}
\left.\frac{\partial T_{P C M}}{\partial x}\right|_{x=0}=\left.\frac{\partial T_{P C M}}{\partial x}\right|_{x=L_{1}}=\left.\frac{\partial T_{P C M}}{\partial x}\right|_{x=L_{1}+L_{2}}=\left.\frac{\partial T_{P C M}}{\partial x}\right|_{x=L_{1}+L_{2}+L_{3}}=0 \\
\left.\frac{\partial T_{M F}}{\partial x}\right|_{x=0}=\left.\frac{\partial T_{M F}}{\partial x}\right|_{x=L_{1}}=\left.\frac{\partial T_{M F}}{\partial x}\right|_{x=L_{1}+L_{2}}=\left.\frac{\partial T_{M F}}{\partial x}\right|_{x=L_{1}+L_{2}+L_{3}}=0
\end{gathered}
$$

\subsubsection{Modelling of metal foam microstructures}

There are still several important parameters for metal foam microstructures that need to be determined for solving the governing equations: Eqs. (10), (11) and (13)-(17). These include: permeability, inertial factor, pore size, metal fibre diameter, effective thermal conductivity, surface area density, and inter-phase heat transfer coefficient. The determination of these parameters is complicated and strongly depends on special microstructures inside metal foams. Several existing models presented by previous 
researchers are employed in this study to obtain these parameters. For simplicity, this subsection only gives the computational formula for effective thermal conductivity, permeability, inertial factor, surface area density and inter-phase heat transfer coefficient. The detailed derivation of all other parameters is given in Calmidi [26] and Zukauskas [29].

Calmidi and Mahajan [27] presented a 2D simplified model of effective thermal conductivity for metal foams, which gave good agreement with test data. However the real microstructures in metal foams are three-dimensional, and therefore a 3D model is preferred in order to get improved accuracy. In this paper, a 3D structured model presented by Boomsma and Poulikakos [30] has been used to deal with the effective thermal conductivity of metal foams. A tetrakaidecahedron [31] was used in their model to approximate metal foam cells, because that is the polyhedron with the minimal surface energy - this is relevant because metal foam cells tend to shrink to the minimal surface when being manufactured by foaming processes. Figure 2 shows the structure of a tetrakaidecahedron, which is a fourteen-face polyhedron comprising six squares and eight hexagons [32]. By using such a polyhedron approximation, Boomsma and Poulikakos [30] obtained a good agreement between model predictions and experimental data on metal foams with porosities from $88 \%$ to $98 \%$. Their model is shown in Eq. (30):

$$
\begin{aligned}
& k_{e}=\frac{\sqrt{2}}{2\left(R_{A}+R_{B}+R_{C}+R_{D}\right)} \\
& R_{A}=\frac{4 \lambda}{\left(2 e^{2}+\pi \lambda(1-e)\right) k_{s}+\left(4-2 e^{2}-\pi \lambda(1-e)\right) k_{f}} \\
& R_{B}=\frac{(e-2 \lambda)^{2}}{(e-2 \lambda) e^{2} k_{s}+\left(2 e-4 \lambda-(e-2 \lambda) e^{2}\right) k_{f}} \\
& R_{C}=\frac{(\sqrt{2}-2 e)^{2}}{2 \pi \lambda^{2}(1-2 e \sqrt{2}) k_{s}+2\left(\sqrt{2}-2 e-\pi \lambda^{2}(1-2 e \sqrt{2})\right) k_{f}} \\
& R_{D}=\frac{2 e}{e^{2} k_{s}+\left(4-e^{2}\right) k_{f}}
\end{aligned}
$$




$$
\begin{aligned}
& \lambda=\sqrt{\frac{\sqrt{2}\left(2-(5 / 8) e^{3} \sqrt{2}-2 \varepsilon\right)}{\pi(3-4 e \sqrt{2}-e)}} \\
& e=0.339
\end{aligned}
$$

In Eqs. (30a) to (30g), $R_{A}, R_{B}, R_{C}$ and $R_{D}$ are the calculated thermal resistances of four different layers inside a tetrakaidecahedron cell. The effective thermal conductivity $k_{e}$ is a result of these four layers being placed in parallel [30]. $k_{s e}$ and $k_{f e}$, which are two important parameters in Eq. (16) and Eq. (17), can be also calculated by assigning $k_{f}=0$ and $k_{s}=0$ in Eq. (30) respectively.

From fitting experimental data, Calmidi and Mahajan [27] also obtained the empirical formula for permeability and inertial factor calculations of metal foams. Since their results showed good agreement with experimental data, this present paper has employed their formula, with Eq. (31) showing permeability and Eq. (32) showing inertial factor respectively:

$$
\begin{aligned}
& \frac{K}{d_{p}{ }^{2}}=0.00073(1-\varepsilon)^{-0.224}\left(\frac{d_{f}}{d_{p}}\right)^{-1.11} \\
& C_{f}=0.00212(1-\varepsilon)^{-0.132}\left(\frac{d_{f}}{d_{p}}\right)^{-1.63}
\end{aligned}
$$

Here, $d_{p}$ denotes the equivalent diameter of metal foam cells, which can be calculated if knowing the pore density: $d_{p}=0.0254$ (meter)/pore density. Pore density is dimensionless and usually measured in ppi (pores per inch). $d_{f}$ denotes the equivalent diameter of metal foam fibres, calculated from

$$
\frac{d_{f}}{d_{p}}=1.18 \sqrt{\frac{1-\varepsilon}{3 \pi}}\left(\frac{1}{1-e^{-(1-\varepsilon) / 0.04}}\right)
$$

Calmidi [26]. To give more accurate calculating results, Eq. (33) has taken into account the non-circular shape of metal fibres by introducing a shape factor.

The surface area density of metal foams $a_{s f}$ is defined as the total surface area $\left(\mathrm{m}^{2}\right)$ of metal fibres within unit volume of metal foam matrix $\left(\mathrm{m}^{3}\right)$, and it can be obtained by 
assuming that all metal fibres have an ideal cylindrical shape (a shape factor was also introduced by Calmidi and Mahajan [27] to consider the non-circularity):

$$
a_{s f}=\frac{3 \pi d_{f}\left(1-e^{-((1-\varepsilon) / 0.04)}\right)}{\left(0.59 d_{p}\right)^{2}}
$$

$h_{s f}$ is the inter-phase heat transfer coefficient between the metal foam struts and PCM, and also needs to be determined. Because the metal foam struts were assumed to have the shape of cylinders, the value of $h_{s f}$ can be approximately calculated by the empirical formulae for the flow across a bank of cylinders [29]:

$$
\begin{gathered}
N u_{s f}=\frac{h_{s f} d}{k_{f}}=0.76 \operatorname{Re}_{d}^{0.4} \operatorname{Pr}^{0.37},\left(1 \leq \operatorname{Re}_{d} \leq 40\right) \\
N u_{s f}=\frac{h_{s f} d}{k_{f}}=0.52 \operatorname{Re}_{d}^{0.5} \operatorname{Pr}^{0.37},\left(40 \leq \operatorname{Re}_{d} \leq 1000\right) \\
N u_{s f}=\frac{h_{s f} d}{k_{f}}=0.26 \operatorname{Re}_{d}^{0.6} \operatorname{Pr}^{0.37},\left(1000 \leq \operatorname{Re}_{d} \leq 2 \times 10^{5}\right)
\end{gathered}
$$

\section{Numerical procedure}

A FVM-based (Finite Volume Method) program has been developed by the authors to solve Eqs. (10), (11) and (13)-(17), which are the governing equations of the current physical problem. The program was compiled and executed under the workspace of Visual Fortran ${ }^{\circledR}$. Coupled heat conduction and natural convection equations were solved simultaneously by employing the SIMPLER algorithm (Semi-Implicit Method for Pressure Linked Equations Revised) [33] in a non-uniform mesh $(1200 \times 200)$. The PLS (Power Law Scheme) [34] was employed to discretise convection-diffusion terms to save computing time whilst ensuring high accuracy. In the $x$-direction (total length: $10.5 \mathrm{~m}$ ), 1200 uniform grids were used, with each grid $0.00875 \mathrm{~m}$ in length, whilst in the $y$ direction (total length: $0.02 \mathrm{~m}$ ), 200 grids were used, with each grid $1.0 \times 10^{-4} \mathrm{~m}$ in length. Mesh independency was examined, and it was found that the difference between the $2400 \times 400$ mesh and the $1200 \times 200$ mesh was only $0.17 \%$, meaning a finer mesh is not needed. Due to different convergence rates in the three metal-foam samples, the 
optimised time step was found to be $5 \times 10^{-3}$ s for the metal foam of $95 \%$ porosity and 10 ppi, $3 \times 10^{-3} \mathrm{~s}$ for the metal foam of $95 \%$ porosity and $30 \mathrm{ppi}$, and $2 \times 10^{-3} \mathrm{~s}$ for the metal foam of $85 \%$ porosity and 30 ppi. Time step independency was also examined, and it was found that for the metal foam of $95 \%$ porosity and 10 ppi, the difference between $2.5 \times 10^{-3} \mathrm{~s}$ and $5 \times 10^{-3} \mathrm{~s}$ was $0.23 \%$; for the metal foam of $95 \%$ porosity and $30 \mathrm{ppi}$, the difference between $1.5 \times 10^{-3} \mathrm{~s}$ and $3 \times 10^{-3} \mathrm{~s}$ was $0.22 \%$; for the metal foam of $85 \%$ porosity and $30 \mathrm{ppi}$, the difference between $1.0 \times 10^{-3} \mathrm{~s}$ and $2 \times 10^{-3} \mathrm{~s}$ was $0.23 \%$. Numerical simulations were set to stop when the difference between two consecutive iterations was less than $10^{-4}$ (i.e. $0.01 \%$ ). The program was run on the high performance $\mathrm{HP}^{\circledR} \mathrm{Z} 1$ Workstation powered by the quad-core Intel ${ }^{\circledR}$ Xeon ${ }^{\circledR}$ processor and 8GB RAM (Random Access Memory). Total computational time was 41.5 hours, 72.3 hours and 108.8 hours for $95 \%$ porosity and $10 \mathrm{ppi}, 95 \%$ porosity and $30 \mathrm{ppi}$, and $85 \%$ porosity and 30 ppi, respectively.

The numerical programming needs to ensure that natural convection only takes place at the grids where the PCM is in its liquid state and does not take place at the grids where the PCM is still in its solid state. This is realised by only assigning the real viscosity value to the grids where the PCM is liquid whilst assigning a viscosity with the value of $10^{10}$ to the grids where the PCM is still solid.

\section{Results and discussion}

\subsection{Validation.}

To verify the numerical simulation for its accuracy and correctness, an experiment has been designed, in which a single-stage PCM was embedded in metal foam, shown in Fig. 3. The test section comprised a piece of rectangular copper foam (with the dimension of $200 \times 120 \times 25 \mathrm{~mm}$ ) with paraffin wax RT58 embedded in it. According to the PCM provider RUBITHERM ${ }^{\circledR}$, the thermo-physical properties of RT58 are melting temperature: $48-62^{\circ} \mathrm{C}$, latent heat of fusion: $181 \mathrm{~kJ} / \mathrm{kg}$, specific heat: $2.1 \mathrm{~kJ} / \mathrm{kg}$, dynamic viscosity: $0.0269 \mathrm{~Pa} \cdot \mathrm{s}$, thermal conductivity: $0.2 \mathrm{~W} /(\mathrm{m} \mathrm{K})$, thermal expansion coefficient: $1.1 \times 10^{-4} \mathrm{~K}^{-1}$. The metal foam was sintered onto a thin copper plate from the bottom side for better thermal contact. Attached to the copper plate was an electrical heater, made of 
flexible silicon with adjustable heat flux, providing continuous and uniform heat flux for the PCM and metal foam. The heater input power could be precisely controlled and measured by a Variac and an electrical power meter (Hameg HM8115-2, accuracy $\pm 0.5 \%)$. This allowed the heat flux used in the test to be calculated through dividing the input power by the surface area of the copper plate.

In this test, nine thermocouples (accuracy $\pm 0.1^{\circ} \mathrm{C}$ ) were placed at different locations $(y=8 \mathrm{~mm}, 16 \mathrm{~mm}$ and $24 \mathrm{~mm}$ respectively, 3 thermocouples were used for each place to get more reliable readings) inside the PCM to monitor the transient temperature variation. Three thermocouples were placed on the copper plate to record the plate temperatures $(y$ $=0 \mathrm{~mm}$ ). Here, $y$ denotes the distance between different locations and the heating plate. Although perfect insulation cannot be guaranteed in the test, the underneath of the heating surface was insulated with Armflex insulation material and other surfaces were insulated by acrylic sheets which were transparent for observation during the tests. The temperatures and the input power were automatically recorded by a data acquisition system. From previous work by the authors [9], the overall uncertainty of the test was estimated at $6.67 \%$.

The numerical results and the corresponding experimental data are compared in Fig. 4 for $y=0$ and $8 \mathrm{~mm}$. Both numerical results and experimental data show that the PCM begins to melt around $t=1200 \mathrm{~s}$ and finish phase change around $t=4000 \mathrm{~s}$. There is good agreement between numerical results and experimental data, and the most probable reason for the small discrepancies between them is that it has been assumed in the model that the PCM has a fixed melting point, similarly to crystal materials. In practice, it is important to note that RT58 melts in a temperature range of $48-62^{\circ} \mathrm{C}$ according to RUBITHERM $^{\circledR}$. As shown in Fig. 4, the temperatures increase more slowly after melting begins, because the heat provided is mainly used for phase change rather than increasing sensible heat. After the state of RT58 has become fully liquid (when temperatures are higher than $62^{\circ} \mathrm{C}$ ), its temperatures begin to increase more rapidly again, because the heat provided is now all used for increasing sensible heat of the PCM. 


\subsection{Natural convection.}

Natural convection was examined by numerical simulations. Figure 5 shows the flow profiles of natural convection for CTES (Cascaded Thermal Storage System) at dimensionless time $=10$ when all three PCMs have finished their melting processes. Dimensionless time is defined as the real time divided by a reference time which equals to the melting time of PCM 2. Three dotted squares in Fig. 5 denote the rectangular enclosures containing PCM 1 (left), PCM 2 (middle) and PCM 3 (right) respectively. Inside each PCM, two eddies are formed: the larger eddy (clockwise) is situated near the left bottom corner whilst the smaller eddy (anti-clockwise) is situated near the right top corner. It is reasonable to have such two eddies in each PCM, for the following reasons: the PCM and HTF temperatures decrease along the $x$-axis (the HTF flow direction), so the PCM on the left has lower density and therefore moves upward whilst the PCM on the right has higher density and therefore moves downward. The larger eddy is caused by temperature differences, and is the dominating eddy. The smaller eddy seems to have been formed by the wake flow of the dominating eddy, and is the non-dominating eddy. None of these eddies is situated near the left top corner, because the PCM near the upper boundary has higher temperature (closer to HTF) lacking of driving forces for natural convection to take place. It can also be noted in Fig. 5 that the dominating eddies, the ones near the left bottom corner, tend to become smaller in size along the $x$-axis, the reason can be attributed to the fact that the temperature differences, which are the driving forces of natural convection, get smaller along the $x$-axis.

The numerical simulation also examined natural convection for MF-CTES (Metal Foam-enhanced Cascaded Thermal Energy Storage). However, the flow velocities caused by buoyancy force are found to be rather low, with an order of magnitude of $10^{-4} \mathrm{~m} / \mathrm{s}$. At first sight, this may seem surprising, but it is still believed to be reasonable, for the following reason [19]. The buoyancy force term $\rho_{f} g \beta \Delta T$, which drives natural convection, has an order of magnitude of $10^{2}$, but in the main drag force term $-\mu_{f} u / K$ (i.e. Darcy term), $\mu_{f} / K$ has an order of magnitude of $10^{6}$. According to Equilibrium of Forces, drag force should have a similar order of magnitude to buoyancy force, and therefore $u$ should have an order of magnitude of $10^{-4}$. The PCMs used in this study has 
high dynamic viscosity of $0.0251-0.0400 \mathrm{~Pa} \cdot \mathrm{s}$ (1000 times higher than air) and low thermal expansion coefficient of $1.1 * 10^{-4} K^{-1}$ (30 times lower than air), so these special physical characteristics result in the velocity driven by buoyancy force being insignificant in this case. Natural convection therefore fails to produce dominant influence on heat transfer for MF-CTES. The similar suppression of natural convection was also found by Stritih [10], who added thirty-two metal fins into PCM to enhance heat transfer. However, he found that the addition of metal fins did not have the desired effects on heat transfer enhancement during melting, with the reason being that natural convection was significantly suppressed by metal fins and the Rayleigh number in his study was not sufficiently high to overcome the large flow resistance.

\subsection{Comparison of equivalent heat exchange rates among STES, CTES and MF-CTES.}

Equivalent heat exchange rates were also obtained from numerical simulations for STES, CTES and MF-CTES. Figure 6 shows the comparison of equivalent heat exchange rates between STES and CTES. It indicates that CTES using cascaded arrangement of PCMs enhances heat transfer by up to $30 \%$ (overall). However, it should be noted that the equivalent heat exchange rates of CTES system is lower than that of STES when PCM 2 finishes melting for two reasons. Firstly the temperatures in CTES increase rapidly (sensible heat) when PCM $2\left(50^{\circ} \mathrm{C}\right)$ finishes phase change. Secondly, when the temperatures in CTES rise rapidly, the temperatures in STES have kept relatively constant because PCM $4\left(55^{\circ} \mathrm{C}\right)$ is still in melting process (latent heat). The rapidly-rising temperatures in CTES have caused the decrease of temperature differences between PCMs and HTF, resulting in a lower heat transfer performance.

The phase change regions of PCM 1, PCM 2, PCM 3 and PCM 4 can also be seen in Fig. 6, which are represented by the horizontal lines. The figure also indicates that PCM 3 uses the most time to finish phase change, because temperature differences for PCM 3 are much smaller than all other PCMs. As temperature differences decrease, PCM 2 and PCM 3 take more time to be melted than PCM 1.

Figure 7 compares the equivalent heat exchange rates of MF-CTES (Metal Foamenhanced Cascaded Thermal Storage) among three copper-foam samples, the properties 
of which are listed in Table 3. Figure 7 indicates that MF-CTES enhances heat transfer by 2-7 times and reduces melting time by $67-87 \%$ compared to CTES. Sample C (85\% porosity) has better heat transfer performance than Sample A and B (both 95\% porosity). This is reasonable because the former has more solid structures, which results in higher effective thermal conductivity; thus it can transfer heat flux more efficiently to PCMs through the metal foam skeleton. Sample B (30ppi pore density) has better heat transfer performance than Sample A (10ppi pore density). This is also reasonable because higher pore density results in larger contact area between PCMs and metal ligaments so that more heat can be transferred. It can therefore be concluded that the metal-foam samples with lower porosity and higher pore density have better heat transfer performance than the ones with higher porosity and lower pore density.

In summary, CTES enhances heat exchange rate by up to $30 \%$ compared to STES; MF-CTES enhances heat exchange rate by 2-7 times compared to CTES, depending on the properties of metal-foam samples (porosity, pore density and $k_{s}$ ).

\subsection{Comparison of exergy efficiency among STES, CTES and MF-CTES.}

Exergy efficiencies were examined by numerical simulations for STES, CTES and MF-CTES. The comparison of exergy efficiencies between STES and CTES is shown in Fig. 8. CTES does not always have higher exergy efficiency than STES $(-15 \%$ to $+30 \%)$. The exergy efficiency of CTES is lower than that of STES in early stages before PCM 4 starts to melt, because PCM 1 and PCM 2 in CTES have delayed temperature rise due to their latent heat. Since lower temperatures mean lower quality of energy, CTES has lower exergy efficiency at this time. However, the situation is changed when PCM 2 finishes phase change and PCM 4 starts phase change. From this time on, the temperatures in CTES begin to increase rapidly (sensible heat) whilst the temperatures in STES keep relatively constant (latent heat), which leads to CTES having a higher exergy efficiency than STES.

Figure 9 compares the exergy efficiencies of MF-CTES among three different copper-foam samples, indicating that Sample A, B and C all have roughly the same exergy efficiency as CTES. It means metal foams cannot further improve exergy efficiency for CTES, but they can help CTES to finish melting more quickly by having a 
much higher heat exchange rate. As seen in Fig. 8 and Fig. 9, all metal-foam samples finish melting more quickly than CTES, with Sample C being the quickest one.

In summary, CTES does not always have higher exergy efficiency than STES (-15\% to $+30 \%$ ); MF-CTES cannot further improve exergy efficiency for CTES, but can help CTES to finish melting more quickly by having higher heat exchange rates (melting time reduced by $67-87 \%$ ).

\subsection{Comparison of exergy transfer rate among STES, CTES and MF-CTES .}

The Second Law of Thermodynamics states that $q$ cannot be $100 \%$ converted into electricity, meaning that heat exchange rate cannot reflect the real efficiency of a TES system. Thus, a new concept of exergy transfer rate $h_{e x}$ has been proposed in this study to evaluate the overall thermal performance of STES, CTES and MF-CTES.

$$
h_{e x}=q \times \eta_{e x}\left(\mathrm{~W} / \mathrm{m}^{2}\right)
$$

$h_{e x}$ is the effective exergy transfer rate, representing how much useful thermal energy is transferred from HTF to PCMs during charging processes.

Effective exergy transfer rates $h_{e x}$ were obtained by numerical simulations for STES, CTES and MF-CTES. Figure 10 shows the comparison of $h_{e x}$ between STES and CTES system, it can be concluded that CTES nearly always produces higher exergy transfer rate (up to 23\%) than STES. It needs to be noted that CTES delivers slightly lower exergy transfer rate than STES, only when PCM 1 starts phase change and after PCM 4 finishes phase change. There are two probable reasons for this. Firstly, when PCM 1 starts its phase change, CTES had lower exergy efficiency than STES despite of CTES having slightly higher heat exchange rate than STES. Secondly, after PCM 4 finishes its phase change, the heat exchange rate of STES is higher than CTES due to the long-time delay of temperature rise (latent heat of PCM 4), but the exergy efficiency STES is much lower than CTES (shown in Fig. 8) due to its low temperatures after phase change.

Figure 11 compares the effective exergy transfer rate $\left(h_{e x}\right)$ of MF-CTES among three different copper-foam samples, indicating that Sample C has the highest $h_{e x}$ than Sample $\mathrm{A}$ and $\mathrm{B}$, and that all metal-foam samples have much higher $h_{e x}$ (by 2-7 times) than CTES. 
In summary, CTES nearly always has higher exergy transfer rates (up to 23\%) than STES; MF-CTES can further increase exergy transfer rates of CTES by 2-7 times.

\section{Conclusions}

The numerical results have shown good agreement with experimental data. Natural convection exists in all the three cases studied: STES, CTES and MF-CTES. Due to low thermal expansion coefficients and high viscosities of PCMs used, natural convection was found to be rather weak in MF-CTES, since metal foams have large flow resistance.

CTES enhances heat exchange rate by up to $30 \%$ compared to STES. MF-CTES enhances heat exchange rate by 2-7 times compared to CTES, depending on the properties of metal-foam samples (porosity, pore density and metal thermal conductivity). Simulation results indicate that the metal foams with lower porosity and higher pore density have better heat transfer performance than the ones with higher porosity and lower pore density.

CTES does not always have higher exergy efficiency than STES $(-15 \%$ to $+30 \%)$. MF-CTES cannot further improve exergy efficiency for CTES, but can help CTES to finish melting more quickly by having higher heat exchange rates (melting time reduced by $67-87 \%)$.

CTES nearly always has higher exergy transfer rate (up to 23\%) than STES. MF-CTES can further increase exergy transfer rate of CTES by 2-7 times.

\section{Acknowledgements}

This work was supported by the UK Engineering and Physical Sciences Research Council (EPSRC grant number: EP/F061439/1), and the National Natural Science Foundation of China (NSFC grant number: 51176110). The authors are grateful to Professor Keith Godfrey for his valuable advice that significantly improved this study. Acknowledgement also goes to the two anonymous reviewers for their professional review comments which have further improved the quality of this study. 


\section{References}

[1] D.A. Neeper, Thermal dynamics of wallboard with latent heat storage, Sol. Energy 68 (2000) 393-403.

[2] A.A. El-Sebaii, A.A. Al-Ghamdi, F.S. Al-Hazmi, A.S. Faidah, Thermal performance of a single basin solar still with PCM as a storage medium, Appl. Energ. 86 (2009) 1187-1195.

[3] R. Domanski, A.A. El-Sebaii, M. Jaworski, Cooking during off-sunshine hours using PCMs as storage media, Energy 20 (1995) 607-616.

[4] S.D. Sharma, T. Iwata, H. Kitano, K. Sagara, Thermal performance of a solar cooker based on an evacuated tube solar collector with a PCM storage unit, Sol. Energy 78 (2005) 416-426.

[5] D. Buddhi, Thermal performance of a shell and tube PCM storage heat exchanger for industrial waste heat recovery, in: Proceedings of the ISES 1997 Solar World Congress, Taejon, Korea, 1997.

[6] H. Michels, R. Pitz-Paal, Cascaded latent heat storage for parabolic trough solar power plants, Sol. Energy 81 (2007) 829-837.

[7] B. Zalba, J.M. Marin, L.F. Cabeza, H. Mehling, Review on thermal energy storage with phase change: materials, heat transfer analysis and applications, Appl. Therm. Eng. 23 (2003) 251-283.

[8] A. Mills, M. Farid, J.R. Selman, S. Al-Hallaj, Thermal conductivity enhancement of phase change materials using a graphite matrix, Appl. Therm. Eng. 26 (2006) 16521661.

[9] C.Y. Zhao, W. Lu, Y. Tian, Heat transfer enhancement for thermal energy storage using metal foams embedded within phase change materials (PCMs), Sol. Energy 84 (2010) 1402-1412.

[10] U. Stritih, An experimental study of enhanced heat transfer in rectangular PCM thermal storage, Int. J. Heat Mass Tran. 47 (2004) 2841-2847.

[11] E.S. Mettawee, G.M.R. Assassa, Thermal conductivity enhancement in a latent heat storage system, Sol. Energy 81 (2007) 839-845.

[12] X. Py, R. Olives, S. Mauran, Paraffin/porous-graphite-matrix composite as a high and constant power thermal storage material, Int. J. Heat Mass Tran. 44 (2001) 2727-2737.

[13] A. Sar1, A. Karaipekli, Thermal conductivity and latent heat thermal energy storage characteristics of paraffin/expanded graphite composite as phase change material, Appl. Therm. Eng. 27 (2007) 1271-1277.

[14] K. Lafdi, O. Mesalhy, A. Elyafy, Graphite foams infiltrated with phase change materials as alternative materials for space and terrestrial thermal energy storage applications, Carbon 46 (2008) 159-168. 
[15] K. Nakaso, H. Teshima, A. Yoshimura, S. Nogami, S. Hamada, J. Fukai, Extension of heat transfer area using carbon fiber cloths in latent heat thermal energy storage tanks, Chem. Eng. Process: Process Intensif. 47 (2008) 879-885.

[16] D. Zhou, C.Y. Zhao, Experimental investigations on heat transfer in phase change materials (pcms) embedded with porous materials, Appl. Therm. Eng. 31 (2011) 970-977.

[17] T. Watanabe, A. Kanzawa, Second law optimization of a latent heat storage system with PCMs having different melting points, Heat Recov. Syst. CHP 15 (1995) 641653.

[18] Y. Tian, C.Y. Zhao, A. Lapkin, Exergy optimisation for cascaded thermal storage, in: Proceedings of the 12th International Conference on Energy Storage (Innostock 2012), University of Lleida, Lleida, Spain, 2012.

[19] Y. Tian, C.Y. Zhao, A numerical investigation of heat transfer in phase change materials (PCMs) embedded in porous metals, Energy 36 (2011) 5539-5546.

[20] H. Mehling, L.F. Cabeza, Heat and cold storage with PCM: Chapter 6 - Integration of active storages into systems, Springer Publication Corporation, Berlin, 2008, pp. 189-191.

[21] Z.X. Gong, A.S. Mujumdar, Thermodynamic optimization of the thermal process in energy storage using multiple phase change materials, Appl. Therm. Eng. 17 (1997) 1067-1083.

[22] H. Shabgard, C.W. Robak, T.L. Bergman, A. Faghri, Heat transfer and exergy analysis of cascaded latent heat storage with gravity-assisted heat pipes for concentrating solar power applications, Sol. Energy 86 (2012) 816-830.

[23] Rubitherm ${ }^{\circledR}$ Technologies GmbH, Germany <http://www.rubitherm.de>.

[24] I. Dincer, M.A. Rosen, Thermal energy storage: systems and applications, second ed., John Wiley \& Sons, West Sussex, U.K., 2010.

[25] J.P. Holman, Heat transfer, eighth ed., McGraw-Hill, New York, pp. 143-144.

[26] V.V. Calmidi, Transport phenomena in high porosity metal foams, Ph.D. thesis, University of Colorado, U.S.A., 1998.

[27] V.V. Calmidi, R.L. Mahajan, Forced convection in high porosity metal foams, J. Heat Trans.- T ASME 122 (2000) 557-565.

[28] C.Y. Zhao, T.J. Lu, H.P. Hodson, Natural convection in metal foams with open cells, Int. J. Heat Mass Tran. 48 (2005) 2452-2463.

[29] A.A. Zukauskas, Convective heat transfer in cross-flow, in: S. Kakac, R.K. Shah, A. Win (Eds), Handbook of single-phase heat transfer, Wiley-Interscience, New York, 1987.

[30] K. Boomsma, D. Poulikakos, On the effective thermal conductivity of a three-dimensionally structured fluid-saturated metal foam, Int. J. Heat Mass Tran. 44 (2001) 827-836. 
[31] W. Thomson, On the division of space with minimum partitional area, Phil. Mag., 24 (1887) 503-514.

[32] J.G. Fourie, J.P. Du Plessis, Pressure drop modelling in cellular metallic foams, Chem. Eng. Sci. 57 (2002) 2781-2789.

[33] S.V. Patankar, Numerical heat transfer and fluid flow, Hemisphere Publishing Corporation, New York, 1980.

[34] S.V. Patankar, A calculation procedure for two-dimensional elliptic situations, Numer. Heat Transfer 4 (1981) 409-425. 


\section{Figure Captions}

Figure 1: STES, CTES and MF-CTES.

Figure 2: Tetrakaidecahedron [32].

Figure 3: The experimental test rig.

Figure 4: A comparison between numerical results and experimental data.

Figure 5: Flow profiles of natural convection for CTES.

Figure 6: A comparison of equivalent heat exchange rates $q\left(\mathrm{~W} / \mathrm{m}^{2}\right)$ between STES and CTES.

Figure 7: A comparison of MF-CTES equivalent heat exchange rates $q\left(\mathrm{~W} / \mathrm{m}^{2}\right)$ among three different metal-foam samples.

Figure 8: A comparison of exergy efficencies $\eta_{e x}(\%)$ between STES and CTES.

Figure 9: A comparison of MF-CTES exergy efficencies $\eta_{e x}(\%)$ among three different metal-foam samples.

Figure 10: A comparison of $h_{e x}$ between STES and CTES.

Figure 11: A comparison of $h_{e x}$ among different metal-foam samples for MF-CTES. 


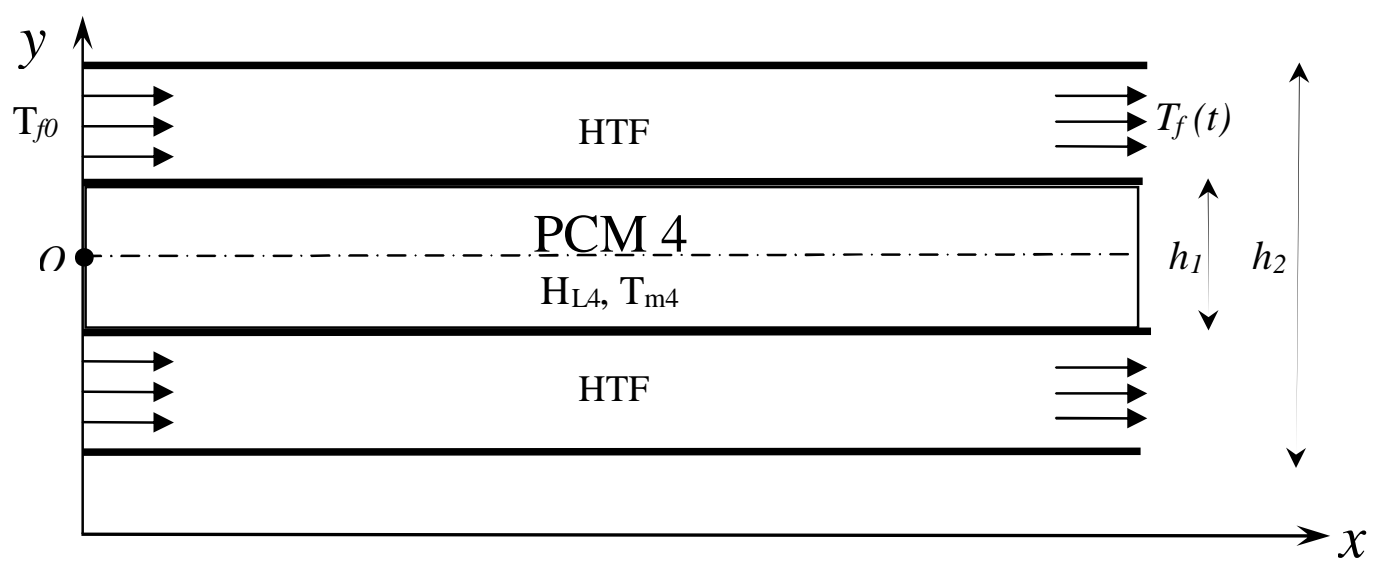

(a) STES

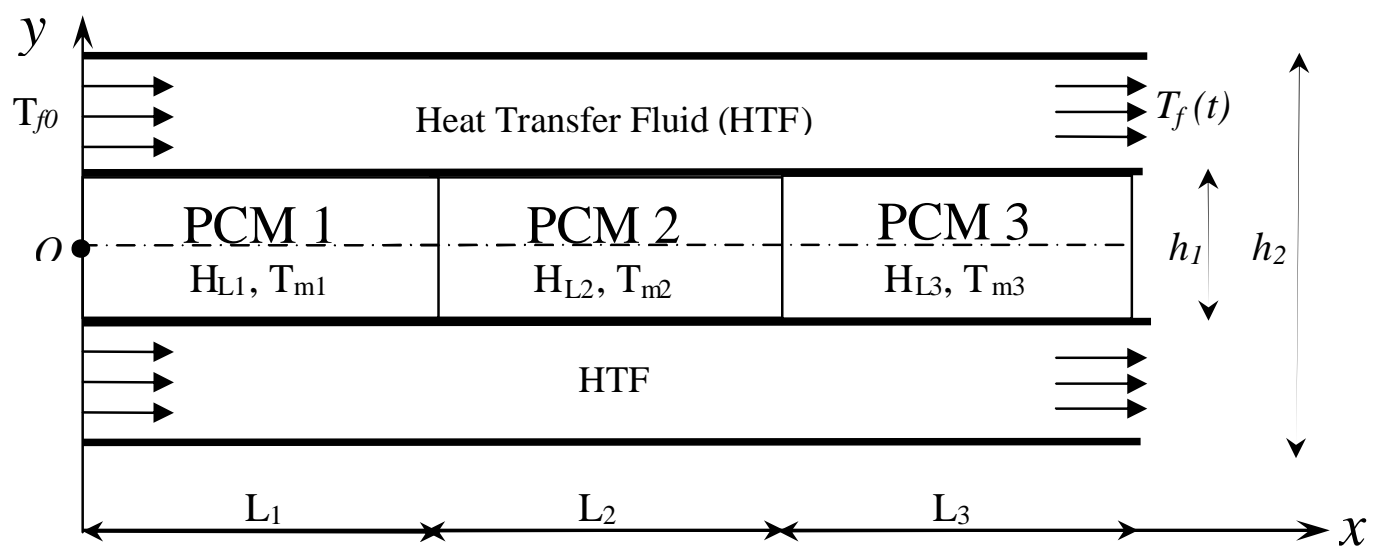

(b) CTES

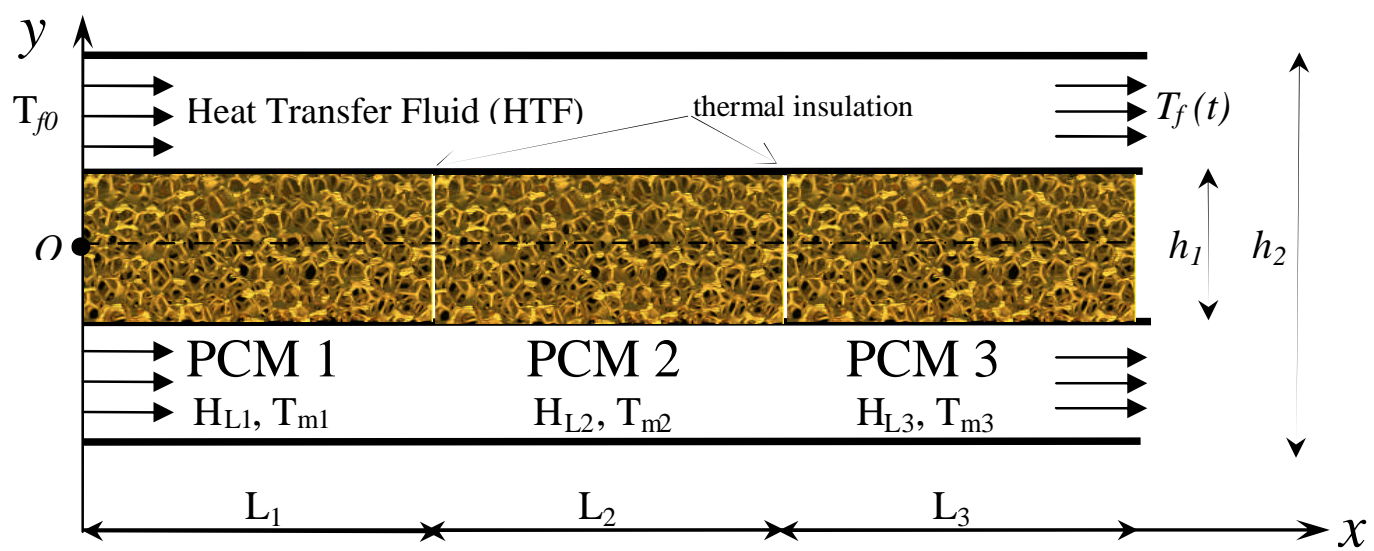

(c) MF-CTES

Fig. 1. STES, CTES and MF-CTES. 


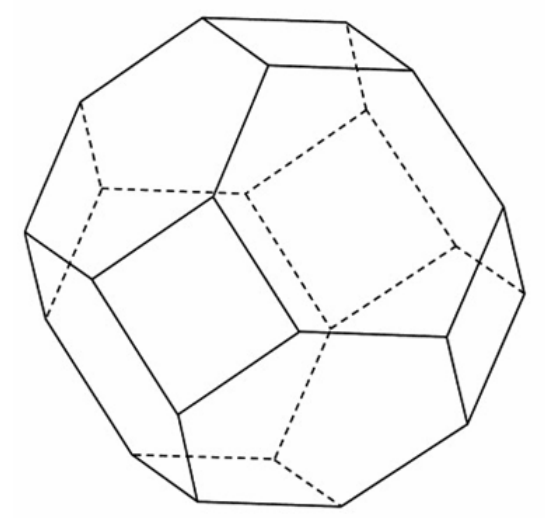

(a) A single tetrakaidecahedron;

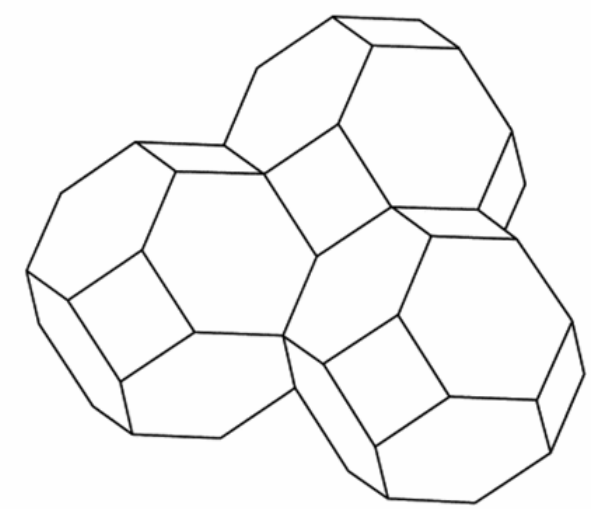

(b) Three tetrakaidecahedrons lapped together

Fig. 2. Tetrakaidecahedron [32].

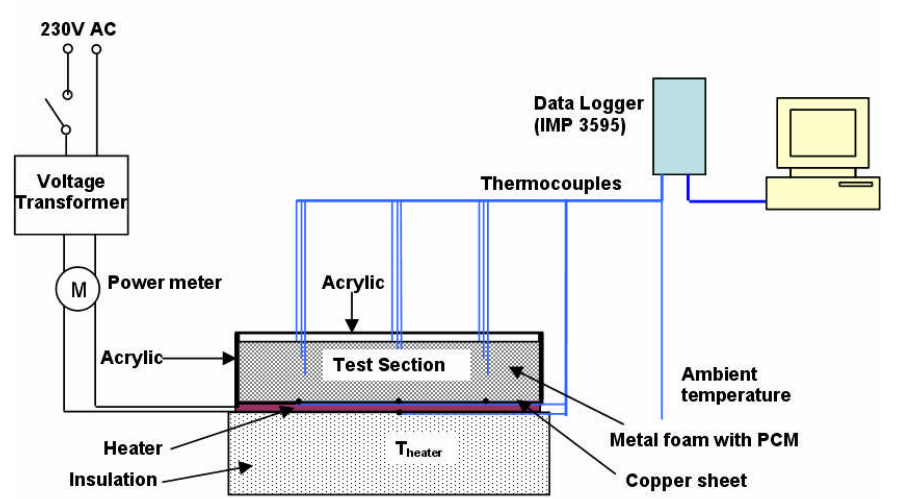

(a) Experimental setup

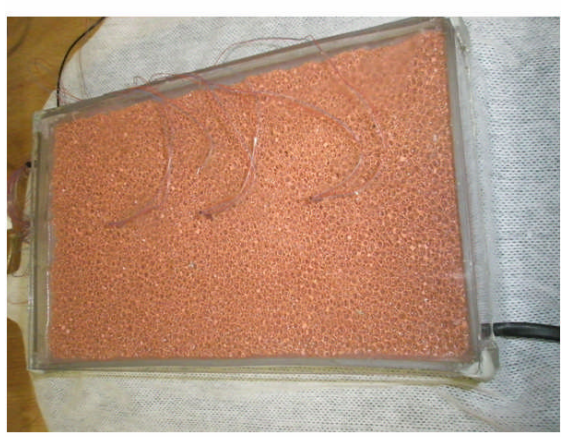

(b) Test section

Fig. 3. The experimental test rig. 


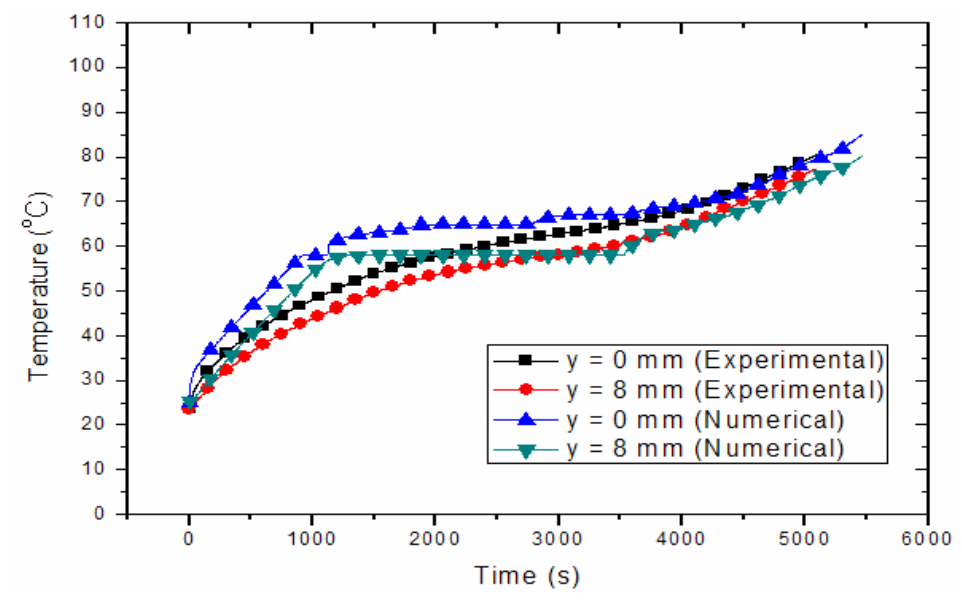

Fig. 4. A comparison between numerical results and experimental data.

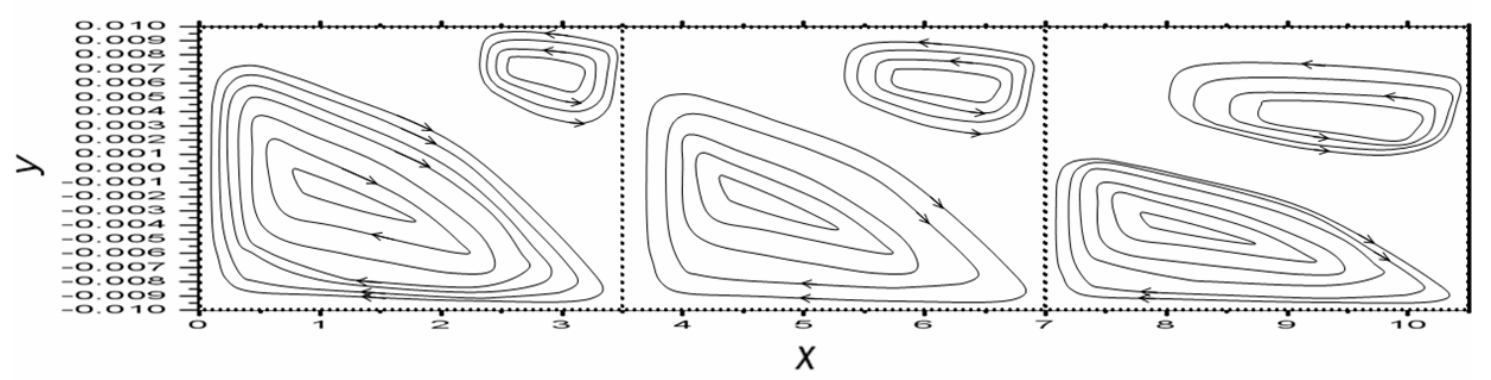

Fig. 5. Flow profiles of natural convection for CTES. 


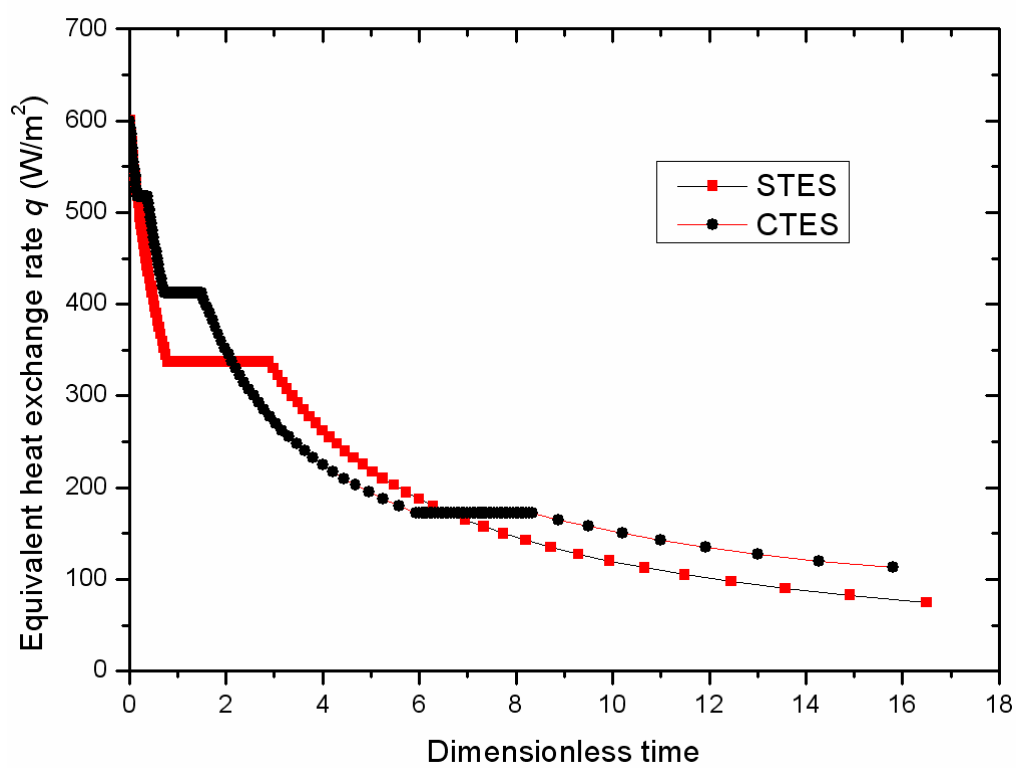

Fig. 6. A comparison of equivalent heat exchange rates $q\left(\mathrm{~W} / \mathrm{m}^{2}\right)$ between STES and CTES.

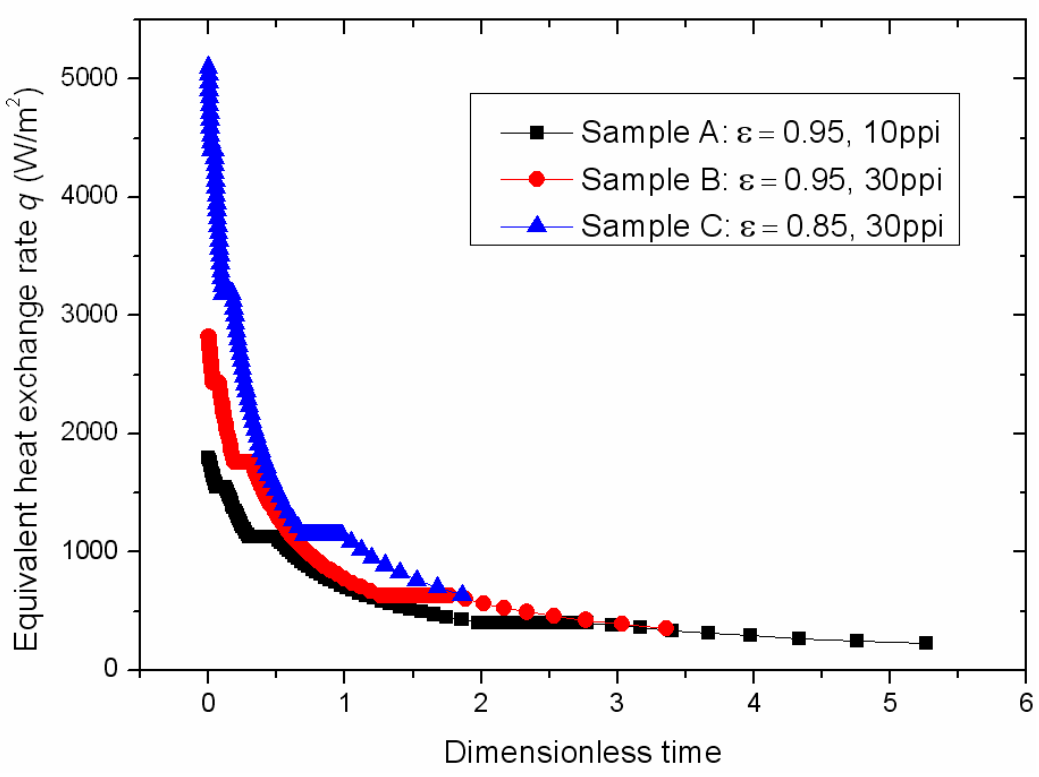

Fig. 7. A comparison of MF-CTES equivalent heat exchange rates $q\left(\mathrm{~W} / \mathrm{m}^{2}\right)$ among three different metal-foam samples. 


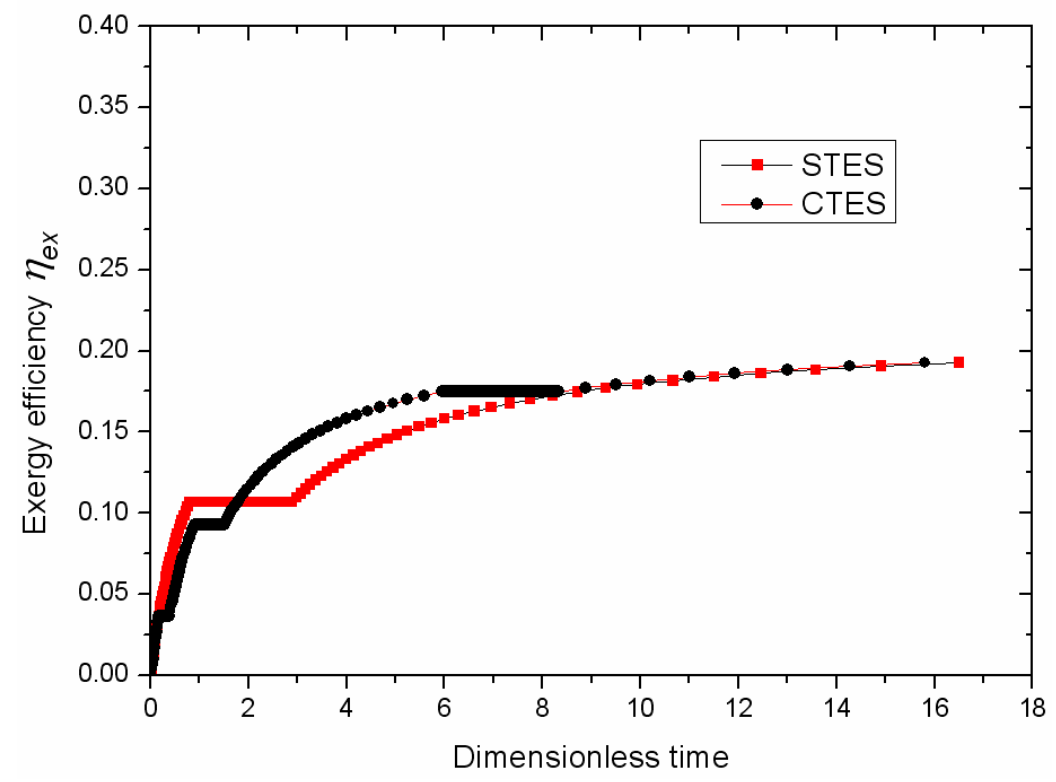

Fig. 8. A comparison of exergy efficencies $\eta_{e x}(\%)$ between STES and CTES.

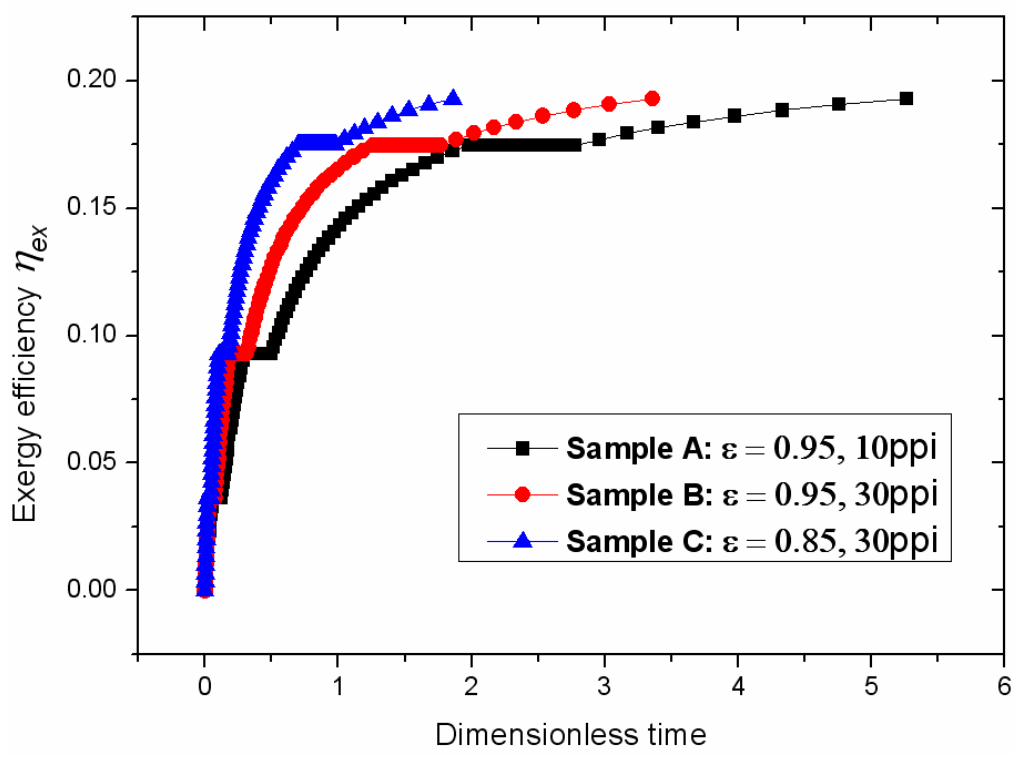

Fig. 9. A comparison of MF-CTES exergy efficencies $\eta_{e x}(\%)$ among three different metal-foam samples. 


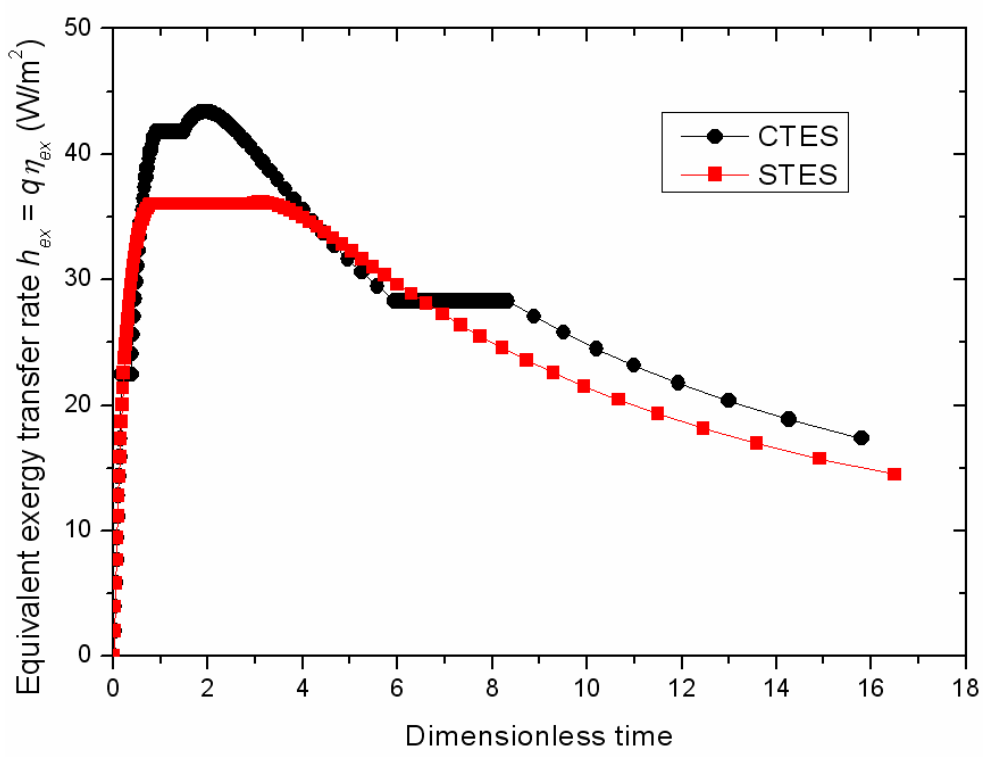

Fig. 10. A comparison of $h_{e x}$ between STES and CTES.

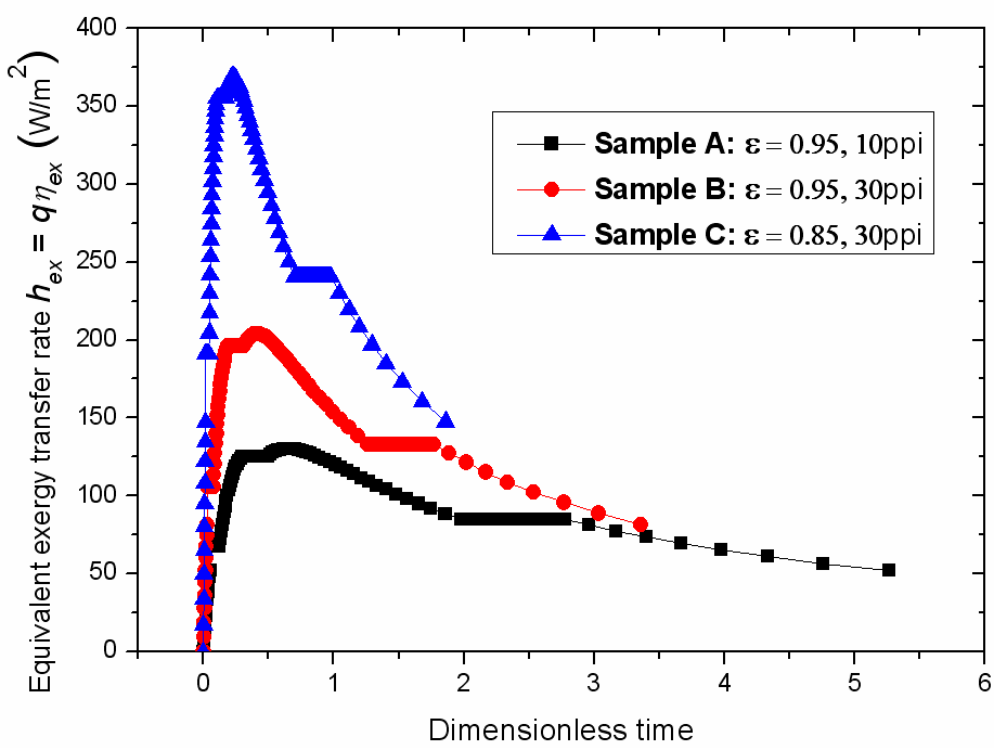

Fig. 11. A comparison of $h_{e x}$ among different metal-foam samples for MF-CTES. 


\section{Table Captions}

Table 1: Thermal properties of PCMs [23].

Table 2: System parameters.

Table 3: Metal foam properties. 
Table 1

Thermal properties of PCMs [23].

\begin{tabular}{lllll}
\hline PCMs & PCM 1 & PCM 2 & PCM 3 & PCM 4 \\
\hline Product code $\left(\right.$ Rubitherm $\left.{ }^{\circledR}\right)$ & RT31 & RT50 & RT82 & RT55 \\
Melting temperature $\left({ }^{\circ} \mathrm{C}\right)$ & 31 & 50 & 82 & 55 \\
Density $\left(\mathrm{kg} / \mathrm{m}^{3}\right)$ & 880.0 & 880.0 & 880.0 & 880.0 \\
Latent heat $(\mathrm{kJ} / \mathrm{kg})$ & 169.0 & 168.0 & 176.0 & 172.0 \\
Specific heat $\left(\mathrm{kJ} / \mathrm{kg}{ }^{\circ} \mathrm{C}\right)$ & 2.1 & 2.1 & 2.1 & 2.1 \\
Thermal conductivity $(\mathrm{W} / \mathrm{m} \mathrm{K})$ & 0.2 & 0.2 & 0.2 & 0.2 \\
Linear thermal expansion coefficient $\left(\mathrm{K}^{-1}\right)$ & $1.1 \times 10^{-4}$ & $1.1 \times 10^{-4}$ & $1.1 \times 10^{-4}$ & $1.1 \times 10^{-4}$ \\
Kinetic viscosity $\left(\mathrm{mm}^{2} / \mathrm{s}\right)$ & 28.57 & 31.20 & 45.45 & 34.08 \\
Dynamic viscosity $(\mathrm{Pa} \mathrm{s})$ & 0.0251 & 0.0275 & 0.0400 & 0.0300 \\
\hline
\end{tabular}

Table 2

System parameters.

\begin{tabular}{ll|ll}
\hline HTF properties & \multicolumn{3}{l}{ System dimension } \\
\hline Density: $\rho$ & $1000 \mathrm{~kg} / \mathrm{m}^{3}$ & $\mathrm{~L}_{1}$ & $3.5 \mathrm{~m}$ \\
Velocity: $v$ & $0.5 \mathrm{~m} / \mathrm{s}$ & $\mathrm{L}_{2}$ & $3.5 \mathrm{~m}$ \\
Dynamic viscosity at $50{ }^{\circ} \mathrm{C}:$ & $0.553 \times 10^{-6} \mathrm{~m}^{2} / \mathrm{s}[24]$ & $\mathrm{L}_{3}$ & $3.5 \mathrm{~m}$ \\
Prandtl number at $50{ }^{\circ} \mathrm{C}: \mathrm{Pr}$ & $3.56[24]$ & $\mathrm{h}_{1}$ & $0.02 \mathrm{~m}$ \\
Specific heat: $\mathrm{c}_{\mathrm{p}}$ & $4.2 \mathrm{~kJ} /\left(\mathrm{kg}{ }^{\circ} \mathrm{C}\right)[24]$ & $\mathrm{h}_{2}$ & $0.04 \mathrm{~m}$ \\
Thermal conductivity: $\lambda_{\text {HтF }}$ & $0.6 \mathrm{~W} /(\mathrm{m} \mathrm{K})[24]$ & $\mathrm{C}$ Characteristic diameter \\
& & $\mathrm{d}=\left(\mathrm{h}_{2}-\mathrm{h}_{1}\right) / 2$ & $0.01 \mathrm{~m}$ \\
Inlet temperature: $\mathrm{T}_{f 0}$ & $100{ }^{\circ} \mathrm{C}$ & & \\
Ambient temperature: $\mathrm{T}_{\mathrm{a}}$ & $20{ }^{\circ} \mathrm{C}$ & & \\
\hline
\end{tabular}


Table 3

Metal foam properties.

\begin{tabular}{llll}
\hline Properties & Porosity $\varepsilon$ & Pore density & $k_{s}$ in Eq. (30) \\
\hline Sample A & $0.95(95 \%)$ & $10 \mathrm{ppi}$ & $350 \mathrm{~W} /(\mathrm{m} \mathrm{K})$ \\
Sample B & $0.95(95 \%)$ & $30 \mathrm{ppi}$ & $350 \mathrm{~W} /(\mathrm{m} \mathrm{K})$ \\
Sample C & $0.85(85 \%)$ & $30 \mathrm{ppi}$ & $350 \mathrm{~W} /(\mathrm{m} \mathrm{K})$
\end{tabular}

